\title{
Bio-compounds production from agri-food wastes under a biorefinery approach: Exploring environmental and social sustainability
}

\begin{abstract}
The society and industrial sectors are facing important challenges regarding the production of bioproducts influenced by social responsibility and environmental consequences. Biorefinery development reports two important goals in the transition towards a bio-based economy: i) the displacement of fossil-based products by biomassbased ones and ii) the setting up of a strong bio-based industry. In this sense, research is being addressed into bio-based products opportunities from biomass residues with the aim of obtaining promising building blocks and high-added value products. Environmental and economic analysis of some bioproducts can be found in the literature. However, social dimension of sustainability is regularly forgotten although many attempts have been performed to standardize and provide the procedures to assess the social dimension.

This chapter presents the production of potential bioproducts from agri-food industrial sector and assesses their sustainability from environmental and social perspectives with the aim of identifying potential hotspots. Since the methodology to assess environmental consequences is well-known and standardised, special attention is paid on the selection of the social indicators considered for analysis. To do so, social impact assessment is conducted through involved stakeholders, surveys and field experiments. Thus, the methodology to assess the social dimension has been formulated in detail considering very different social well-being based indicators.
\end{abstract}

Keywords: Environmental profile; Life cycle assessment; Oligosaccharides; social impacts; Succinic acid. 


\section{List of authors}

Sara González-García ${ }^{1 *}$, Patricia Gullón ${ }^{2}$ and Beatriz Gullón ${ }^{1}$

1 Department of Chemical Engineering, School of Engineering, Universidade de Santiago de Compostela. 15782- Santiago de Compostela, Spain.

2 Chemical and Environmental Engineering Department, University of the Basque Country, 20018 - San Sebastián, Spain.

*Corresponding author: Tel.: +34 881816806; E-mail address: sara.gonzalez@usc.es

\section{Short biographies}

Dr. Sara González (female). Chemical engineer as degree (USC, 2005), she got her PhD in 2009. She is postdoctoral researcher at the University of Santiago de Compostela. Her main research topics include the sustainability assessment applying life cycle assessment and carbon footprint in industrial, forestry, agricultural and food sectors. These research activities have produced $2 \mathrm{PhD}$ theses (currently, she is co-director of 3 Ph.D. theses), 90 papers published in international journals, 7 book chapters and 3 national publications. She has an H-index of 26 (with 1860 total citations by SCOPUS).

Dr. Patricia Gullón (female) Food Science and Technology as degree (UVigo, 2006), she got her PhD in 2011. She is postdoctoral researcher at the University of Basque Country. Her main research line is focused on the obtaining of value-added bioproducts from lignocellulosic materials under an integral biorefinery perspective. She is codirector of $2 \mathrm{PhD}$ theses (ongoing), 2 master theses (completed). Her CV includes 32 papers published in international journals, 6 book chapters, 3 proceedings as well as more 50 contributions to international conferences. She has an h-index of 15 (with 946 total citations by SCOPUS).

Dr. Beatriz Gullón (female) Food Science and Technology as degree (UVigo, 2006), she got her PhD in 2011. She is postdoctoral researcher at the University of Santiago de Compostela. Her main research topic is focused on the exploitation of natural compounds, byproducts and derived extracts in terms of their potential biological properties. Her CV includes 59 papers published in international journals, 6 book chapters as well as more 65 contributions to international conferences. She has an hindex of 18 (with 726 total citations by SCOPUS). 
Index

1. Introduction

2. Top bioproducts with social interest

2.1. Food industry

2.2. Chemical industry

3. Materials and Methods

3.1. Description of environmental assessment

3.2. Description of social assessment

3.3. Case studies

3.3.1. Oligosaccharides and antioxidants production from agri-food industry waste

3.3.2. Succinic acid production from agri-food industry waste

3.4. Life Cycle Inventory data acquisition

4. Results and discussion

4.1. Environmental sustainability of bioproducts

4.1.1. Oligosaccharides and antioxidants production from agri-food industry waste

4.1.2. Succinic acid production from food industry waste

4.2. Social sustainability of bioproducts

5. Conclusions and future Outlook

6. Acknowledgements

7. References 


\section{Introduction}

The public environmental awareness, the outstanding increase in population and the concerns with negative environmental impacts from conventional products derived from fossil sources have prompted a necessity for more sustainable production systems. Sustainable development is considered one of the most challenging policy concepts ever developed (Spangenberg, 2004). Despite the sustainability concept is open to debate (Bond and Morrison-Saunders 2011), three dimensions should be addressed that are environmental protection, economic growth and social equality (Iribarren et al., 2016) in agreement with the United Nations (2015). However, studies consider that the time perspective should be considered. It should be in line with Griggs and colleagues (Griggs et al., 2013) who suggested reformulating the definition of sustainable development reported by the Brundtland Commission as "development that meets the needs of the present while safeguarding Earth's life-support system, on which the welfare of current and future generations depends". Therefore, environmental conditions have to be identified that facilitate successful human development and establish acceptable ranges for the biosphere to remain in that state.

The integration of environmental and economic analysis is known as ecoeconomy or eco-efficiency and it is related with the use of energy and resources in an efficient way. Iribarren and colleagues establish that although eco-efficiency is associated with sustainability (ISO, 2012), other issues are also connected such as consumption patterns and population development (Iribarren et al., 2016).

However, social dimension of sustainability is commonly forgotten although many efforts have been performed to standardize and provide the procedures to include it under the multidimensionality of life cycle assessment (Norris et al., 2012; Norris, 2014). Socio-economy and Corporate Social Responsibility (CSR) of an institution are closely linked involving aspects such as the establishment of security policies, social and community aids and programs of employee training, among others (Searcy, 2010; Blaga, 2013), which could be related to the achievement of a socio-environmental equilibrium. Nevertheless, social and environmental dimensions are considered contrasting aims, since social sustainability requires a minimum of economic growth whereas environmental sustainability sets an upper limit to this growth. Moreover, economic growth increases the average income but it does not automatically reduce the inequalities in the society (Spangenberg, 2004). For this reason, the adopted policies 
should focus on the enhancement of existing synergies and the development of balanced criteria to avoid overemphasizing one dimension with respect to the other (Spangenberg, 2004).

Although many methods are available in the literature to assess the sustainability (Jørgensen et al., 2008; Norris et al., 2012; 2014), they cannot be applied in a generic way. Moreover, different approaches can be identified according to the impact categories and/or indicators (midpoint or endpoint) included (Jørgensen et al., 2008). Therefore, research is being carried out in order to go beyond the traditional three pillars and define the sustainability in terms of alternative or additional dimensions. This is the case of the Prosuite project (Blok et al., 2013) set up by the European Commission as part of the $7^{\text {th }}$ Framework program, in which five dimensions have been proposed to assess the sustainability of new technologies: human health, social well-being, prosperity, natural environment and exhaustible resources from a Life Cycle Assessment (LCA) approach. According to it not only quantitative but also qualitative indicators for environmental and social analysis should be managed.

Among the societal challenges of the Horizon 2020, the bio-based industries are essential elements of the European economic, environmental and societal policy. These challenges involve the transition from fossil-based European industries towards bioresource-based ones. For this, it is necessary the substitution of conventional industrial processes and products by environmentally friendly bio-based ones, the development of integrated biorefineries and the search of potential markets for biobased products. These industries will contribute to the sustainability development through the production systems with enhanced ecosystem services, zero waste and adequate societal value contributing.

The project Biorefinery Euroview has concretized the biorefinery concept as follows: "Biorefineries could be described as integrated biobased industries using a variety of technologies to make products such as chemicals, biofuels, food and feed ingredients, biomaterials, fibres and heat and power, aiming at maximizing the added value along the three pillars of sustainability (Environment, Economy and Society)".

The development of an integrated biorefinery based on biowastes would allow to accomplish some of the five dimensions considered on the sustainable development: i) environmental sustainability, through the valorisation whole residues based on the zerowaste concept; ii) economic sustainability, by means of manufacturing multiple high 
added value products which could enter different markets; iii) social sustainability, since this approach would benefit different sectors by means the creation of qualified jobs and covering the increasing demands of consumers in bio-based products (Fava et al., 2013).

The agri-food processing industries generate huge amounts of wastes which constitute a cheap source of high added value bio-compounds, bio-based chemicals and bio-fuels.

Increasing the use of agri-food wastes can derive into a range of challenges such as the no competition for land for food production or urban expansion, the reduced impact on ecosystems and biodiversity, the no-contribution to water scarcity and no impact in food prices.

In this sense, the industrial sector is putting its attention into organic waste valorisation boosted by the necessity to transform the fossil-based production processes towards the bioresource-based ones. There is a series of chemicals which can be obtained from the agri-food wastes following the biorefinery concept and that are considered top by the US Department of Energy (2004). Among these top chemicals, the succinic acid $\left(\mathrm{C}_{4} \mathrm{H}_{6} \mathrm{O}_{4}\right)$ was identified as one of the ten "top" chemicals that could be obtained from biorefinery carbohydrates (Bozell and Petersen, 2010; Werpy and Petersen, 2004). Succinic acid or butanedioic acid is a striking renewable platform chemical mostly due to its functionality and valuable derivatives (López-Garzón et al., 2014).

A biorefinery that supplements its production processes of low value biofuels with high value biobased chemicals can facilitate efforts to moderate non-renewable fuel consumption while simultaneously providing the necessary financial motivation to encourage growth of the biorefining industry. However, social dimension is not always considered. Therefore, the inclusion of social aspects into the environmental life cycle assessment (LCA) of products and systems is mandatory (Jørgensen et al, 2008), ensuring safe working conditions and respecting for workers' rights. Figure 1 schematically displays some interrelations in the value chain of sustainably integrated biorefinery systems. According to it, social dimension in biorefinery systems create jobs, improve health and provide leisure for the society (Budzianowski and Postawa, 2016). 


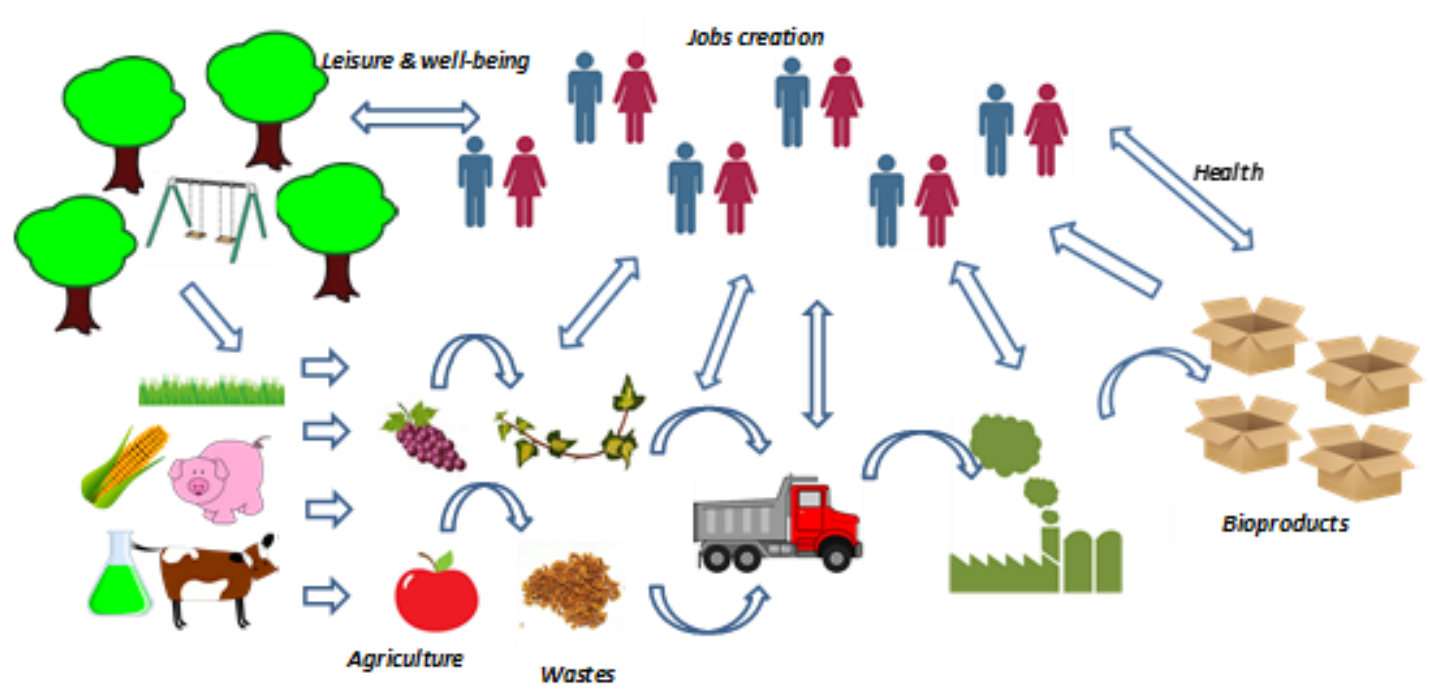

Figure 1. Social and environmental interrelations in the assessment of biorefinery systems (Adapted from Budzianowski and Postawa, 2016)

The study aims to deliver a broad LCA framework, taking into account two pillars of sustainability i.e., environmental and social. Thus, an integrated methodology from a holistic approach that supports decisions that product developers, policy makers and businesses must perform is proposed for the sustainability analysis. To do so, the methodology has been applied to specific case studies of biobased products with current social and industrial interest: oligosaccharides and antioxidants with an important interest in food and pharmaceutical sectors as well as succinic acid, one of the platform chemicals labelled as top chemical.

\section{Top bioproducts with social interest}

Biomass resources can be considered potential raw materials to produce highadded value products. In this sense, special attention is being paid in promising sugarbased chemicals and materials which could be considered as an economic driver for a biorefinery concept.

In recent years, numerous studies and research activities are being carried out regarding the production of novel products with promising market potential and considered substitutes for existing petrochemicals as well as platform chemicals. This is the case of biobased chemicals derived from carbohydrates (Bozell and Petersen, 2010) and saccharides extracted from the hemicellulosic fraction (Gullón et al., 2018). Thus, 
the attention in this chapter has been focused into both bioproducts categories also supported by the society's interest on their production.

Nowadays, it is not only important for the companies to improve the efficiency in their manufacturing processes with the aim of reducing waste production and resources consumption but also to increase safety of workers, customers and environment as well as to offer in the markets novel products with the same or even improved properties than conventional ones.

\subsection{Food industry}

The agricultural food processing generates more than 250 mil MT/year of byproducts including stems, leaves, seeds, shells, pomace, bran, besides of food that do not meet the quality standards and do not make it into the production chain (Panouillé et al., 2007; Fava et al., 2015). In the past, these by-products were directly disposal to land, or were used for low added-value applications (composting or animal feed), causing environmental problems and also negative impacts on the sustainability of the food sector (Sala et al., 2017). Nowadays, the obtaining of different high value products from agri-food by-products is an important ongoing field of research. These by-products are excellent sources of bioactive compounds including dietary fibre, antioxidants, oligosaccharides, vitamins, pectin, enzymes, pigments, organic acids inter alia, of special interest for the food industry (Galanakis 2012; Banerjee et al., 2017; Sagar et al., 2017).

These phytochemicals show interesting properties such as prebiotic, antibacterial, antihypertensive, antioxidant and cardioprotective capacity, and its consumption is related with beneficial effects to health or reduction the risk of diseases (Gullón et al., 2014; Muthaiyan et al., 2012). In the past few years, consumers have a higher health interest and more concern for the life quality, boosting the market of these natural biomolecules.

It is important to highlight that the use of agri-food by-products for obtaining different bioactive compounds is key to improve the environmental and economical sustainability of food sector (Fava et al., 2013; Alañón et al., 2017).

In this section the obtaining of several bioactive compounds from agri-food byproducts is described. 
An interesting group of compounds that has seen increased its demand by the consumers in the last decade is integrated by pectin, oligosaccharides and dietary fibre which are recognized by their beneficial effects already listed above. Apple and citrus processing industries produce big amounts of wastes with a great potential to be valorised since they contain a wide variety of these bioactive compounds (Ndayishimiye and Chun, 2017). Several research works have focused on obtaining these biocompounds from apple pomace and citrus peels (Gullón et al., 2011; Gómez et al., 2013; Wang et al., 2014; Li et al., 2014). Apart from citrus peels and apple pulp, others agro-industrial sub-products such as sugar beet pulp, peach peels or pulps of grapes and pumpkin have also been found to contain high amounts of pectin and dietary fiber (Martínez et al., 2009; Müller-Maatsch et al., 2016; Banerjee et al., 2017; Sagar et al., 2017). Another interesting by-product for obtaining pectin is the one generated in the exotic fruits processing industry (Ayala-Zavala et al., 2010). Different industrial wastes associated with the production of olive oil were also evaluated for production of different mixtures of oligosaccharides with prebiotic potential (Fernández-Bolaños et al., 2004; Ruíz et al., 2017). With regard to the processing of cereals, it is worth highlighting the by-products generated in the grinding of wheat and de-hulling of rice, which are rich in dietary fibres including glucuronoarabinoxylans (Gullón et al., 2014; Gullón et al., 2010; Hollmann and Lindhauer, 2005).

The phenolic compounds are another important group of bioactive molecules which are present in large quantities in a great variety of agri-food by-products (Mohdaly et al., 2010; Ribeiro da Silva et al., 2014; Ndayishimiye and Chun, 2017). Polyphenols have received a great deal of attention because of their capacity to combat the generation of free radicals in vivo, preventing cell damage and oxidative stress. Antioxidants also play a role as preservatives due to their ability to scavenge free radicals and prevent oxidation reactions in food (Deng et al., 2012; Banerjee et al., 2017). In this sense, over the last few decades there has been a growing interest towards the production of natural antioxidants as an alternative to the less-safe synthetic antioxidants. Thus, it has been promoted the obtaining of these phytochemicals from residues derived from the food sector (Moreira et al., 2016). In fact, the peels of several fruits (e.g., apple, citrus, banana, watermelon, peaches and pineapple) are an excellent source of natural antioxidants such as phenolic acids, flavonoids, flavonols, catechins, tannins, procyanidins, anthocyanins, among others (Marín et al., 2017; Sagar et al., 
2017; Banerjee et al., 2017). Grape skins and seeds, by-products of the juice and wine industries, are also rich sources of antioxidants compounds (González-Paramás et al., 2004; Teixeira et al., 2014; Barba et al., 2016). The tropical exotic fruit by-products contain also a great variety of antioxidant compounds that could be used for the formulation of nutraceuticals (Ayala-Zavala et al., 2011). Other successful example byproduct that can show a good profitability for the extraction of phenolic compounds is olive-derived biomass (Nadour et al., 2012; Lama-Muñoz et al., 2014; Ruiz et al., 2017). The potato processing industry also generates significant amounts of waste that have been investigated for the extraction of phenolics compounds (Singh et al., 2011; Sabeena Farvin et al., 2012).

In addition, the recovery of different pigments that can be used as food coloring agents has been widely investigated using fruits processing wastes (Ayala-Zavala et al., 2011). Anthocyanins can be efficiently extracted from grape pomace or banana bracts (Monrad et al., 2014; Pazmiño-Durán et al., 2001). Citrus peel has also been utilized for the recovery of carotenoids (Ndayishimiye and Chun, 2017; Agócs et al., 2007). Tomato industries produce large amounts of a by-product, known as tomato pomace, consisting mainly of skins and seeds (Lenucci et al., 2013). This by-product is an excellent source for the extraction of lycopene (Seifi et al., 2013; Baysal et al., 2000), and in recent years, this commercial pigment has received significant attention because of their important health benefits (Seifi et al., 2013; Lavelli and Torresani 2011).

Another interesting alternative for the valorisation of the agri-food by-products is the production of different enzymes through fermentation processes (Padma et al., 2012; Sandhya and Kurup, 2013). Several research works have been focused in the use of many agro-industrial wastes for the production of various important enzymes in food industries. The apple pulp has a high content in cellulose and pectin so it is an adequate substrate for the production of cellulase and polygalacturonase (Vilas-Boas et al., 2002; Zheng and Shetty, 2000). Others pectin rich fruit by-products like banana peel, orange peel, mango peel, and pineapple peel have also been evaluated for polygalacturonase production (Padma et al., 2012). Potato peel has been also assessed to produce cellulases and amylases (dos Santos et al., 2012; Mushtaq et al., 2017).

The fruit by-products also can serve for the extraction of flavours and aromas (Sagar et al., 2017). One of these aromas is the vanillin which is widely used in the food industry. The microbial bio-tranformation of pineapple wastes has been reported for the 
production of vanillin (Lu et al., 2014). Essential oils can be also obtained from of citrus peel or grape seeds.

\subsection{Chemical industry}

Building blocks, reagents, intermediates ... are classifications of chemicals with interest for industry and society, which could be obtained under a green approach. Petroleum, natural gas, sulphur dioxide, nitrogen and oxygen are considered raw materials for the production of commodity chemicals and intermediates destined to final products such as preservatives, fertilisers, dyes, food packaging and pharmaceuticals. However, all of them could be obtained from biomass feedstocks (starch, cellulose, hemicellulose, lignin, oil and protein) under a value chain approach (Werpy et al., 2004).

The use of carbohydrates as starting materials for chemicals production is well supported (Kamm, 2009). The lignocellulosic feedstock based biorefinery, also known as green biorefinery, is being favoured in research, development, and industrial implementation since the production of lignocellulosic biofuels and chemicals is driven by the increasing global consumption and depletion of fossil resources (Kemppainen, 2015). Among the variety of possibilities from glucose-accessible microbial and chemical products, lactic acid, succinic acid and levulinic acid are particularly favourable intermediates for the generation of industrially relevant product family trees.

However, the biorefinery concept that relies on terrestrial crops is under hot debate due to impacts on economy as well as its competition with energy, water and land for food/feed production (Cesário et al., 2018). Therefore, the use of marine resources (e.g. macro and micro algal biomass) and agri-food residues is attracting the attention of researchers (Cesário et al., 2018). The former is known as a sustainable source of simple sugars commonly destined to bioethanol fermentation. However, alternative uses are receiving attention in the literature in recent years regarding the saccharification and hydrolysation of its sugars since they are carbohydrate-rich feedstocks (Cesário et al., 2018). Levulinic acid, lactic acid, citric acid, polyhydroxyalkanoates, 2,3-butanediol or even succinic acid could be obtained from algal biomass (Ramesh and Kalaiselvam, 2011; Hwang et al., 2012; Mazumdar et al., 2013; Alvarado-Morales et al., 2015; Alkotaini et al., 2016; Marinho et al., 2016). The 
high growth rates associated with its high photosynthetic rate (Jung et al., 2013), the absence of lignin and low presence of hemicellulose support the interest on this type of raw material. Nevertheless, efforts should be conducted in terms of improving the existing lignocellulosic-based technologies (hydrolysis and fermentation) adapted to algal biomass due to the type of carbohydrates (e.g. alginate). Moreover, genetic transformation is also performed to increase the carbohydrate content (Mikami, 2013).

Regarding the use of agri-food residues, their exploitation is speculated to increase in the future mainly by emerging technologies not only on second generation biofuels production but also on high-added value products recovery (Wiloso et al., 2014; Gullón et al., 2018). In 2004, the US Department of Energy identified the "top" chemicals (up to 50) that could be obtained from biorefinery carbohydrates considering lignocellulosic biomass. In 2009, Bozell and Petersen (2010) reduced the list into ten chemicals which are ethanol, furans, glycerol (and derivatives), biohydrocarbons, lactic acid, succinic acid, hydroxypropionic acid, levulinic acid, sorbitol and xylitol. From that list, only ethanol, furfural, glycerol and sorbitol are available at commercial scale from a biochemical approach.

Organic acids (i.e., lactic acid, succinic acid, hydroxypropionic acid and levulinic acid) are produced in a minimum number of steps from biorefinery carbohydrate streams and have drawn much attention by industrial biotechnology due to their multiple applications as well as they are precursors of several industrially-valuable products (Chun et al., 2014). A demanding challenge for the biological production of organic acids at commercially meaningful high titters is to deal with the toxic effects of those acids on the cell growth and cellular metabolisms of the microorganisms producing the acids (Chun et al., 2014).

Although lactic acid has several uses, some of the most expanding ones are the production of biodegradable plastics and textile fibres by means of its polymerisation into polylactic acid (Ilmén et al., 2007) as well as platform chemical for the production of green solvents by means of its esterification into lactate esters (Aparicio and Alcalde, 2009). Succinic acid or butanedioic acid is considered a building block obtained by the biochemical transformation of biorefinery sugars (Pinazo et al., 2015; Zhan et al., 2017). Succinic acid is an outstanding renewable platform chemical mostly due to its functionality and valuable derivatives (López-Garzón et al., 2014). Succinic acid is precursor of well-known petrochemical products such as 1,4-butanediol, 
tetrahydrofuran, $\gamma$-butyrolactone and polybutylene succinates among others. Moreover, succinic acid presents multiple industrial applications in biodegradable polymers (polyesters, polyamides and polyesteramides), foods (e.g., acidulant, flavorant and sweetener), fine chemicals and pharmaceuticals (Sauer et al., 2008; Pateraki et al., 2016). Regarding hydroxypropionic acid, it is obtained from 3hydroxypropionaldehyde. Its catalytic dehydration produces acrylic acid, acrylate esters and other commodity chemicals (van Maris et al., 2004). Finally, levulinic acid is of interest as a building block and platform chemical due to its simple and high production yield from the hydrolysis of some types of saccharides such as glucose or fructose (Fitzpatrick, 2004; Muranaka et al., 2014). Among its potential uses, it can be used to make materials such as plastics and rubbers as well as intermediate for medical supplies.

\section{Materials and Methods}

\subsection{Description of environmental assessment}

LCA is considered one of the most developed tools for looking holistically at the environmental consequences linked to the life cycle of production processes, products or services. In this sense, it is widely used by environmental professionals and policy makers for the systematic evaluation of the environmental dimension of sustainability. Numerous studies focused on chemical processes have been environmentally assessed following the ISO 14040 (2006) guidelines (Kralisch et al., 2014; Al-Salem et al., 2014). In addition, several authors have explored the implementation of LCA methodology in environmental studies of biorefineries (Neupane et al., 2013; Gilani and Stuart, 2015; González-García et al., 2016; 2017) being bio-succinic acid also analysed (Moussa et al., 2016; Smidt et al., 2016). Therefore, its applicability in this area is justified. In this chapter, LCA methodology has been followed in detail considering the specification reported in the ISO standards (ISO 14040, 2006).

Among the steps defined within the Life Cycle Impact Assessment (LCIA) of the standardised LCA tool (ISO 14040, 2006), classification and characterisation steps have been followed in this study to analyse the production of the bioproducts under assessment from an environmental approach.

The characterisation factors reported by the Centre of Environmental Science of Leiden University - CML 2001 method v2.05 (Guinée et al., 2001) have been 
considered in this study for the analysis. The following impact categories have been evaluated (see Figure 2): global warming potential (GWP), acidification potential (AP), eutrophication potential (EP) and photochemical oxidation potential (POP). The choice of these impact categories is that all together give a complete and comprehensive overview of the environmental effects related to the bioprocesses under evaluation.

Finally, normalisation factors established by the mentioned method (Guinée et al., 2001) have been considered in order to obtain an environmental dimension index per bioproduct. However, since the bioproducts under study are not substitutes, it does not make sense the comparison between their environmental profiles.

The SimaPro v8.2 (PRé Consultants, 2017) software has been managed for the computational implementation of the Life Cycle Inventory data in all the case studies (Goedkoop et al., 2013).

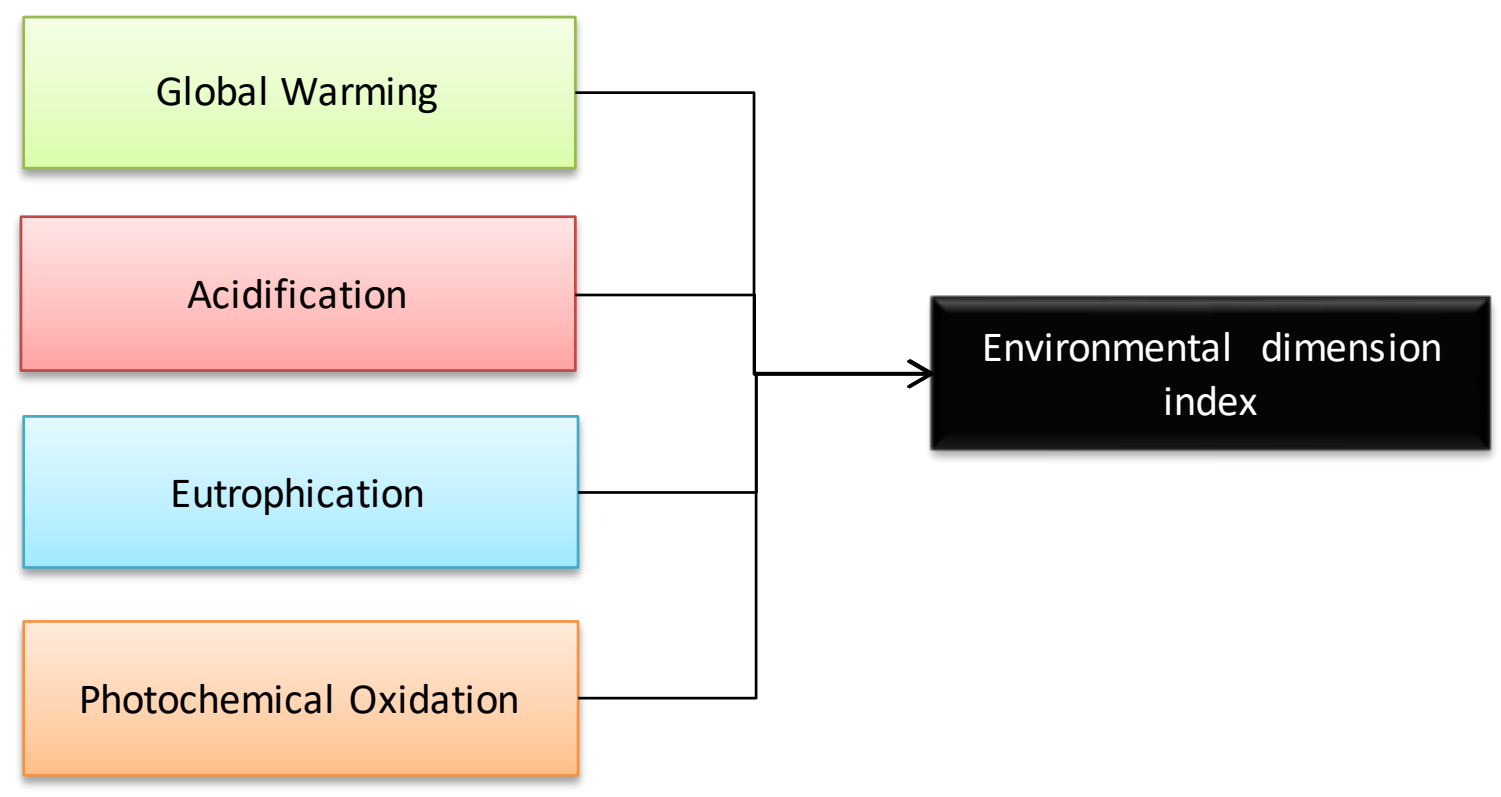

Figure 2. List of categories selected for assessing the environmental dimension

\subsection{Description of social assessment}

A social life cycle assessment (S-LCA) is a method that can be used to assess the social and/or sociological aspects of products or services along the life cycle. Since this method follows a life cycle assessment approach, it looks at the extraction and processing of raw materials, manufacturing, distribution, use, reuse, maintenance, recycling and final disposal (UNEP-SETAC, 2009). 
S-LCA makes use of generic and site-specific data or indicators, which can be quantitative, semi-quantitative or qualitative such as annual salary, working hours per week, forced labour, discrimination, child labour, women-to-men ratio of employees or number of accidents. Quantitative indicators describe the analysed issue based on numbers, whereas qualitative indicators describe an issue using words. Finally, semiquantitative indicators categorise qualitative indicators into a "YES/NO" form or a scoring system.

Therefore, it perfectly complements the social dimension in sustainability assessments. The UNEP-SETAC guidelines recommend a similar method within the framework of the ISO 14040 (2006), including the four stages of goal and scope definition, life cycle inventory, life cycle impact assessment and interpretation of results (UNEP-SETAC, 2009). Thus, the guidelines describe social impacts as "consequences of positive or negative pressures on social endpoints" (UNEP-SETAC, 2009).

Treatment of social well-being is relatively new in the field of quantitative impact assessment at product and technology level. Thus, the measurement of the impact on social well-being with a life cycle perspective needs special attention. The social impact assessment should include impacts on human well-being which include a broad range of pathways that affect the quality of life of people (Weidema, 2008) such as i) autonomy of people - directly related with forced labour, ii) safety and security associated with unemployment and iii) equality - negatively impacted by income distribution, fair salary or equal opportunities.

There are many possible indicators to address impacts on social dimension and, in this study, eight main indicators have been selected as most relevant for the bioproducts under study and taking into account the availability of required data. These indicators are displayed in Figure 3 classified in terms of their potential contribution to the different social pathways that affect the quality of life and considering the different stakeholder categories mentioned by UNEP-SETAC (UNEP-SETAC, 2009) to which they can contribute.

Finally, a social dimension index (see Figure 3) has been estimated taking into account an equal contribution from the three social pathways (autonomy, safety, security and tranquility and, equality). 


\section{Operationalisation of indicators}

Assessing in more detail the eight indicators chosen, the following subcategories within indicator and social pathway should be required (if possible) from stakeholders:

\section{$\underline{\text { Safety, security and tranquillity }}$}

- Working hours: total working hours per month or year in bioproducts related plants. This issue should be really interesting to be considered in the analysis however, it has not been included due to lack of good quality data.

- Health \& safety: information regarding the performance of safety tests, availability of safety test for checking, regulations...

- Transparency: information regarding the availability of consumer service, consumers' complaints files, supply of information to the consumers regarding characteristics of the bioproduct.

\section{Equality}

- Fair salary: annual salary of bioproducts workers as well as identification of differences in the salary between men and women.

- Equal opportunities/discrimination: identification of women-to-men differences not only in the salary for similar work but also in the labour force participation.

\section{$\underline{\text { Autonomy }}$}

- Benefits of bioproduct: information regarding the perception of added value of the bioproduct in comparison with fossil alternatives, valuation of the use of agri-food wastes as raw material instead of other sources.

- Public commitments to sustainability issues: public perception of environmental benefits linked to the bioproduct in comparison with fossil one, public perception of agri-food wastes use to bioproducts obtaining.

- Contributions to economic development: public perception of bioproducts, public perception of agri-food wastes use to bioproducts obtaining, potential market of bioproducts. 


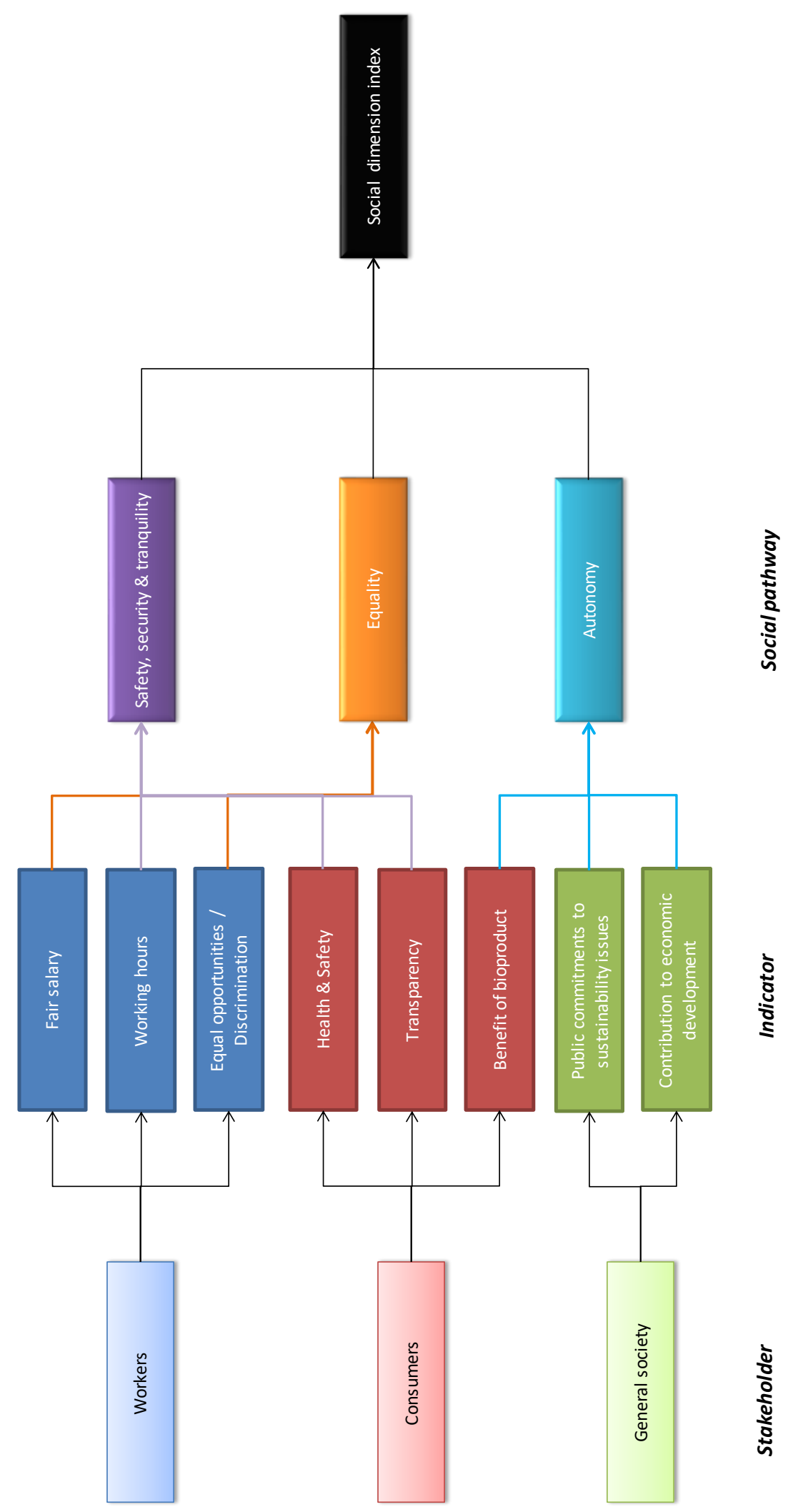

Figure 3. List of stakeholders, indicators and social pathways selected to assess the social dimension

\subsection{Case studies}




\subsubsection{Oligosaccharides and antioxidants production from agri-food industry waste}

In the last decade, consumers have a greater concern for health, which has driven the demand of novel functional foods enriched with bioactive compounds (Grajek, Olejnik, and Sip, 2005). These bioactive compounds can be obtained from low-cost agricultural and agro-industrial by-products using environmentally friendly technologies (Gullón et al., 2014).

In this chapter, it has been considered the obtaining of high added value products from vine shoots. This waste from the wine sector have been traditionally poorly exploited, however various studies focused on its composition suggests presence of a wide range of bioactive compounds such as oligosaccharides and antioxidant compounds with potential nutraceuticals and pharmaceutical applications (Dávila et al., 2016; Gullón et al., 2017).

The valorisation of this residue into high added value products has been performed considering three steps which are described below:

Firstly, vine shoots are subjected to a hydrothermal processing (SS1) to separate its main structural components (hemicellulosic oligosaccharides and antioxidants compounds in liquid stream and a solid fraction rich in cellulose and lignin).

The liquid phase is processed to obtain two different streams of bioactive compounds, one containing oligosaccharides and other one with antioxidants. For this purpose, this liquid phase is extracted with ethyl acetate, and aqueous and organic phases are separated by decantation. The organic phase was vacuum evaporated to obtain an extract rich in antioxidant compounds and aqueous phase is concentrated using membranes to obtain other stream rich in oligosaccharides. These stages are part of the subsystem "Bioactive Compounds Recovery".

Finally, the solid phase is subjected to alkaline delignification to recovery separately the cellulose and lignin. This stage is based on a mild thermal treatment using $\mathrm{NaOH}$ to solubilise the lignin and provides a solid phase enriched into cellulose. Several steps of filtration and washing with water are involved in this stage.

A summarised scheme of the production of high added value compounds considered in this study is displays in Figure 4. 


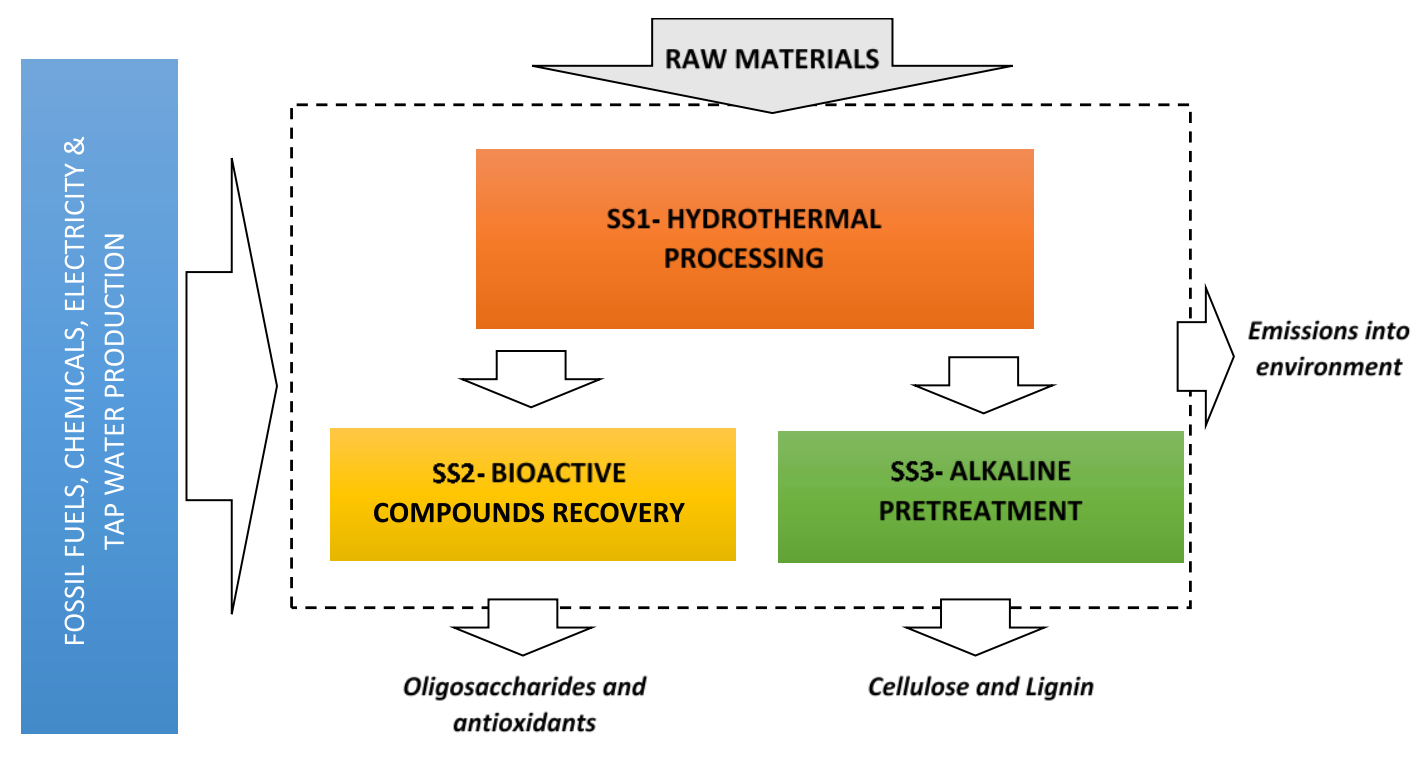

Figure 4. System boundaries and stages involved in vine shoots-based oligosaccharides and antioxidants production system

\subsubsection{Succinic acid production from agri-food industry waste}

Succinic acid or butanedioic acid $\left(\mathrm{C}_{4} \mathrm{H}_{6} \mathrm{O}_{4}\right)$ is an outstanding renewable platform chemical supported by its functionality and valuable derivatives (López-Garzón et al., 2014). There is a wide recent literature focused on its production and interest as chemical building block (Zhang et al., 2017; Moussa et al., 2016; Smidt et al., 2016; Pinazo et al., 2015; Li et al., 2010). It can be obtained from biochemical transformation of biorefinery sugars (bacterial fermentation of carbohydrates), from a range of feedstocks and considering multiple microorganisms (Orjuela et al., 2013). In addition, environmental benefits are linked to its bioproduction since carbon dioxide is needed by microorganisms (carbon dioxide fixation involved in the reductive TCA cycle) (Pateraki et al., 2016; Bechtold et al., 2008).

In this chapter, it has been considered the production of succinic acid from apple pomace as raw material, which is considered as a residue in apple and juice industries.

The valorisation of apple pomace into succinic acid has been performed considering three main steps, which are summarised below:

Firstly, the apple pomace is received from the juice factory and it is warehoused in hoppers. Next, it is dried at atmospheric pressure in a tray drier $\left(60^{\circ} \mathrm{C}\right)$ with the aim of reducing its moisture content and increasing its lifespan. The dried raw material is 
stored in silos at $20^{\circ} \mathrm{C}$ and atmospheric pressure to guarantee its conservation and to avoid the proliferation of plagues. These activities are involved in the Raw material reconditioning and storage stage (SS1).

Secondly, the sugars fermentation takes place under a simultaneous saccharification and fermentation -SSF step (SSF stage, SS2). As difference to other valorisation routes, the microorganism used in this process (A. succinogenes) requires the consumption of carbon dioxide and glucose as carbon sources.

Finally, the purification of the succinic acid (Purification stage, SS3) is performed in order to obtain succinic acid at industrial grade (pure A-grade, i.e., $\geq 99.5 \% \mathrm{wt}$ ). Multiple activities are involved in this stage such as membranes ultrafiltration, reactive extraction with tri-n-octilamine (TOA) in 1-octanol and vacuum distillation (and crystallisation) to obtain the desired pure succinic acid stream. A summarised scheme of the succinic acid production sequence under study is depicted in

\section{Figure 5.}

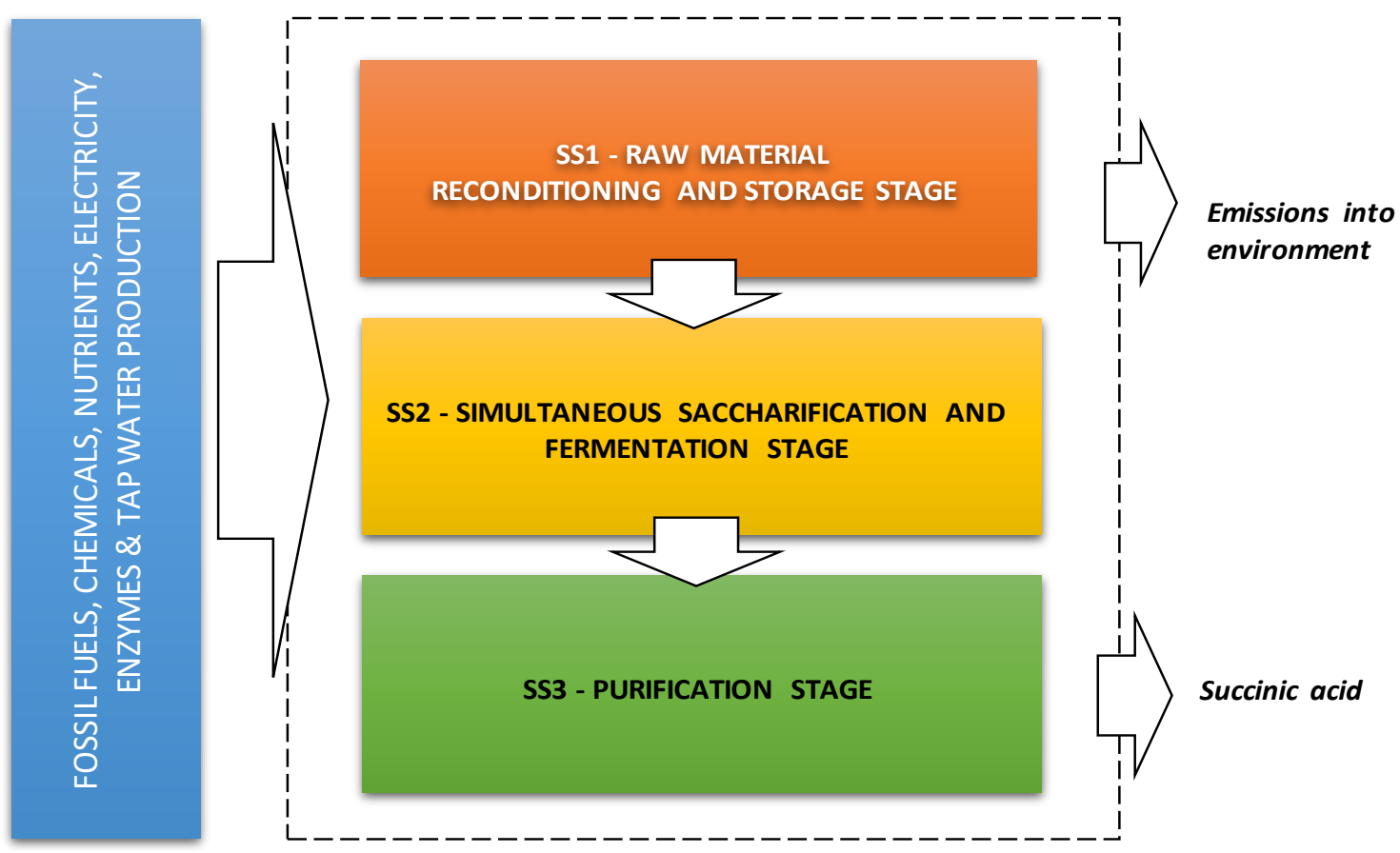

Figure 5. System boundaries and stages involved in apple pomace-based succinic acid production system 


\subsection{Life Cycle Inventory data acquisition}

A reliable environmental assessment requires the collection of high quality inventory data. A consistent environmental assessment requires the collection of high value life cycle inventory (LCI) data.

In this study, inventory data for the foreground systems (i.e., direct inputs and outputs for each process or step) correspond with average data taken from the modellisation at full-scale of each biorefinery scenario. To do so, information from the laboratory has been used to design and model the production sequences.

Primary data correspond to electricity requirements in the different units: reactors, centrifuges, membranes, orbital shakers, distillers, freeze-dryers, etc as well as to the use of chemicals, enzymes, nutrients and tap water, depending on the valorisation route. Secondary data have been also managed but only for the background processes such as production of electricity, chemicals, nutrients and tap water, which have been taken from the Ecoinvent database ${ }^{\circledR}$ v3.1 (Wernet et al., 2016). Regarding enzymes production, inventory data have been taken from Gilpin et al. (2017).

Ancillary activities such as wastewater and solid waste treatment have been also included within the system boundaries in order to compute the environmental impacts from the different wastes management. Inventory data corresponding to wastewater treatment activities have been taken from Doka (2007). Regarding solid wastes, it has been assumed their management in sanitary landfills (Doka, 2007).

\section{Results and discussion}

\subsection{Environmental sustainability of bioproducts}

\subsubsection{Oligosaccharides and antioxidants production from agri-food industry waste}

Figure 6 displays the characterisation results per kg of valorised agri-food waste as well as the environmental dimension index associated to the production system. It is important to bear in mind that $170 \mathrm{~g}$ of hemicellulosic oligosaccharides and $27 \mathrm{~g}$ of antioxidant extract are obtained per $\mathrm{kg}$ of vine shoots valorised. 


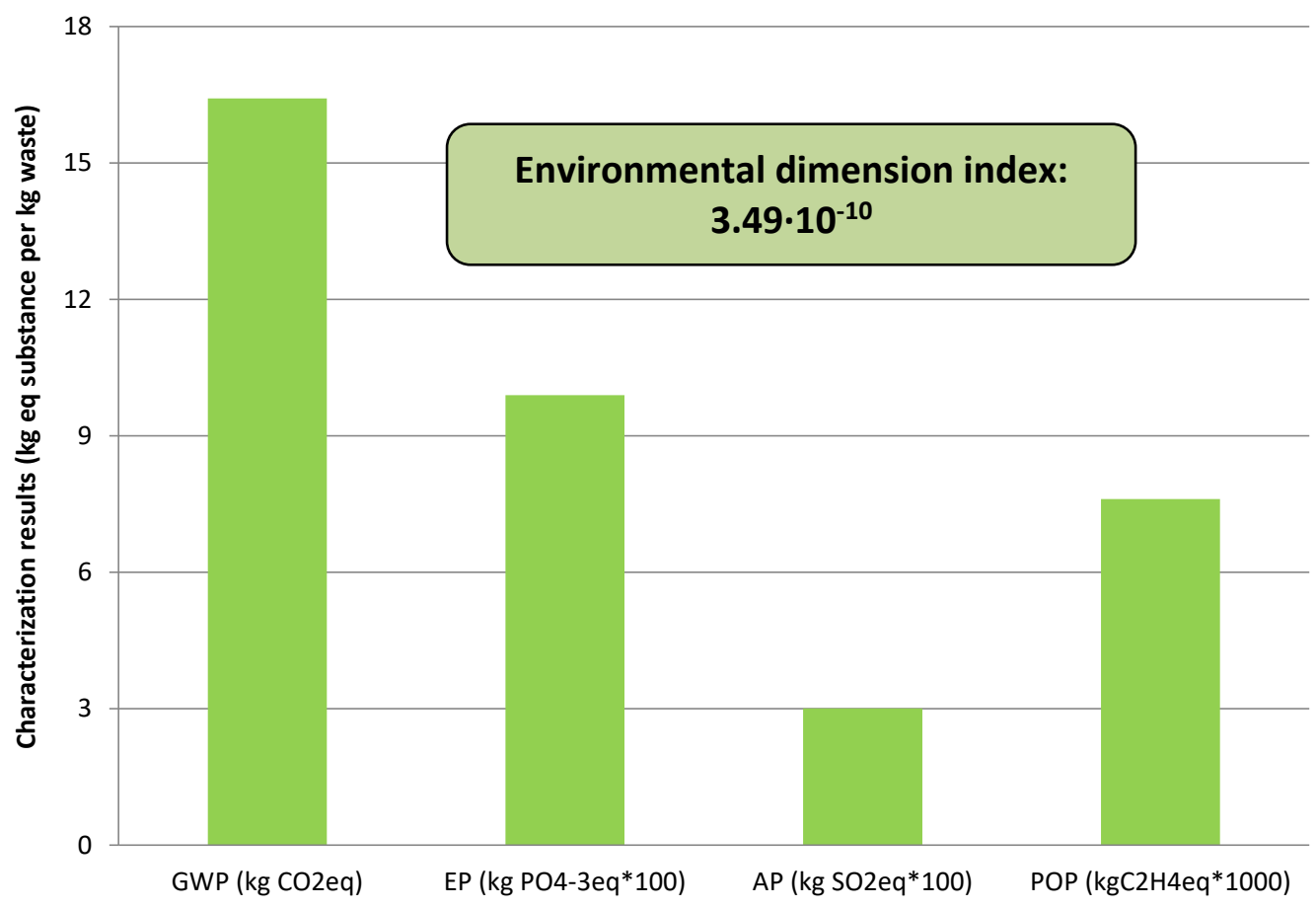

Figure 6. Environmental profile associated with the production of both oligosaccharides and antioxidants from vine shoots

Assessing in detail the contributions to the environmental profile displayed in Figure 6, two involved stages can be identified as environmental hotspots: the bioactive compounds recovery (SS2) and the alkaline pretreatment (SS3) as displayed in Figure 7.

The bioactive compounds recovery stage includes the hemicellulosic oligosaccharides extraction with ethyl acetate, the further extractive chemical recovery with the production of the antioxidants extract and the final oligosaccharides freezedrying (Gullón et al., 2018). Production of electricity requirements in the freeze-drying and in the vacuum evaporation to recover the ethyl acetate and to obtain the extract is considered the main responsible of environmental burdens derived from this stage with contributing ratios higher than $98 \%$ of impacts from SS2. 


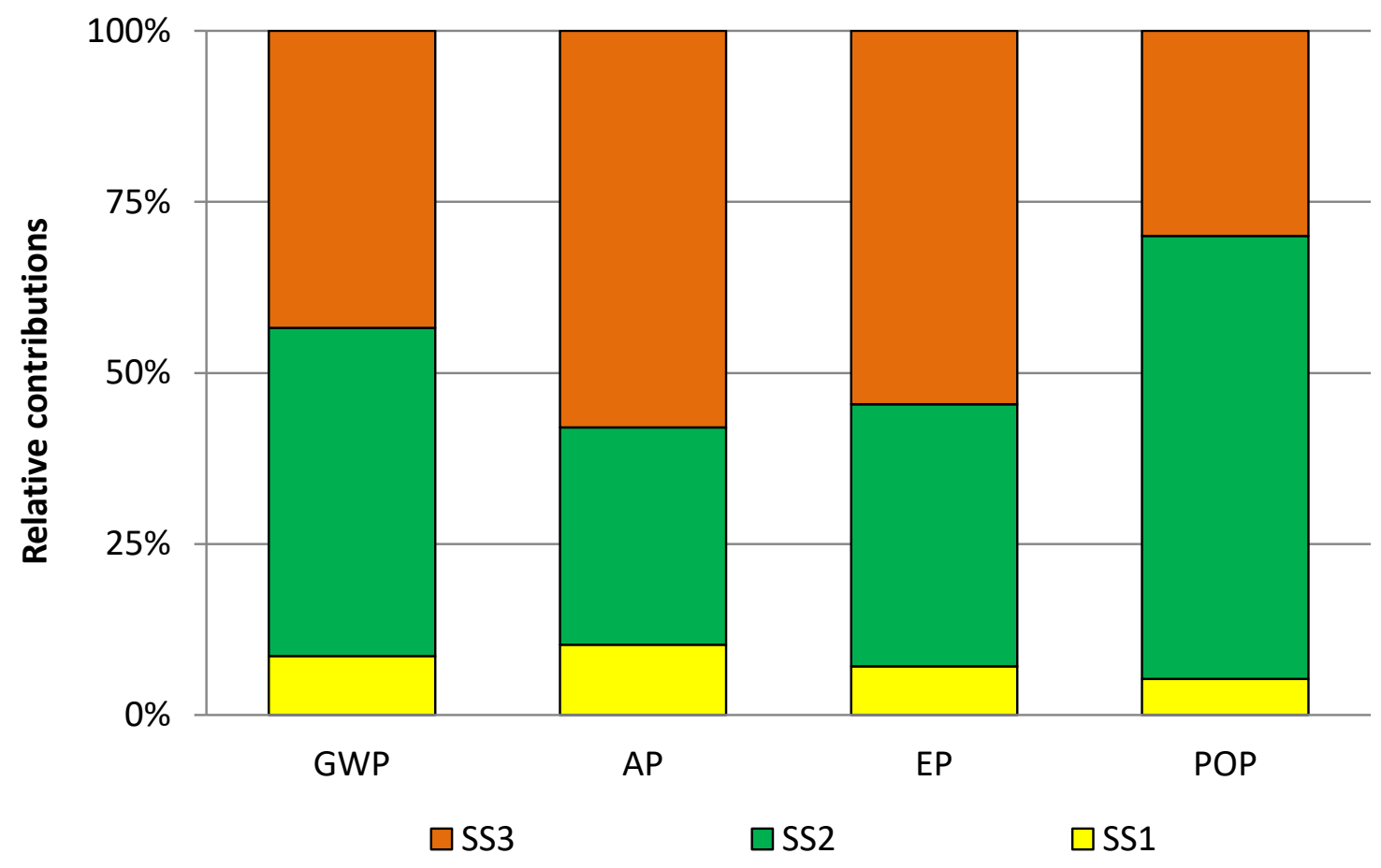

Figure 7. Distribution of impacts per stages involved in the valorisation sequence

The alkaline pretreatment stage manages the solid fraction from SS1, where it is subjected to alkaline delignification and different filtration and precipitation steps to obtain lignin and cellulose as co-products. Production of electricity requirements in the delignification process is also considered as an environmental hotspot together with the production of the sulfuric acid required to precipitate the lignin from the black liquor. Contributions from the former are $96 \%, 86 \%, 75 \%$ and $86 \%$ of GWP, AP, EP and POP of total SS3. Contributions from the latter are $2 \%, 12 \%, 55$ and $12 \%$ of GWP, AP, EP and POP of total SS3.

Thus, electricity and sulfuric acid production play a key environmental role (see Figure 8) and environmental improvements should be focused on optimising their requirements. 


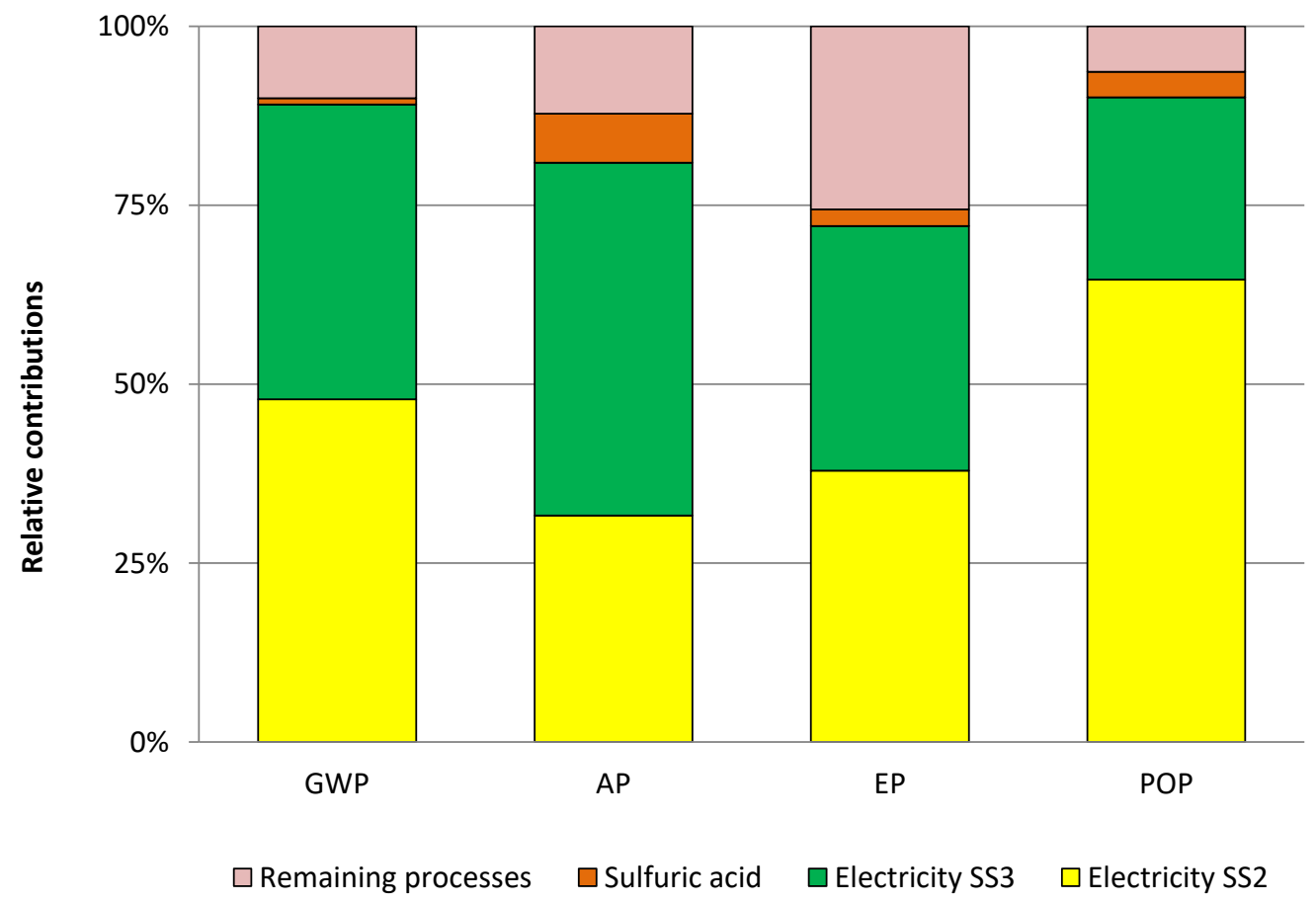

Figure 8. Identification of environmental hotspots

\subsubsection{Succinic acid production from food industry waste}

Figure 9 displays the characterisation results per $\mathrm{kg}$ of valorised waste as well as the environmental dimension index associated with the production system. It is important to bear in mind that $0.55 \mathrm{~kg}$ of succinic acid is obtained per $\mathrm{kg}$ of apple pomace valorised.

Having in mind the contributions from the different stages involved in the production system to the global environmental profile, the purification stage is the environmental hotspot since it is responsible for contributions higher than $93 \%$ in all the categories considered for analysis. The rationale behind the large environmental burdens derived from this stage is associated with the use of organic chemicals required in the extraction process as well as the large electricity requirements mostly in the distillation process. Although $95 \%$ of total organic chemicals dose required in the extraction is recovered in the distillation process and recycled to the system, the effect from chemicals waste into the environmental profile is outstanding. 


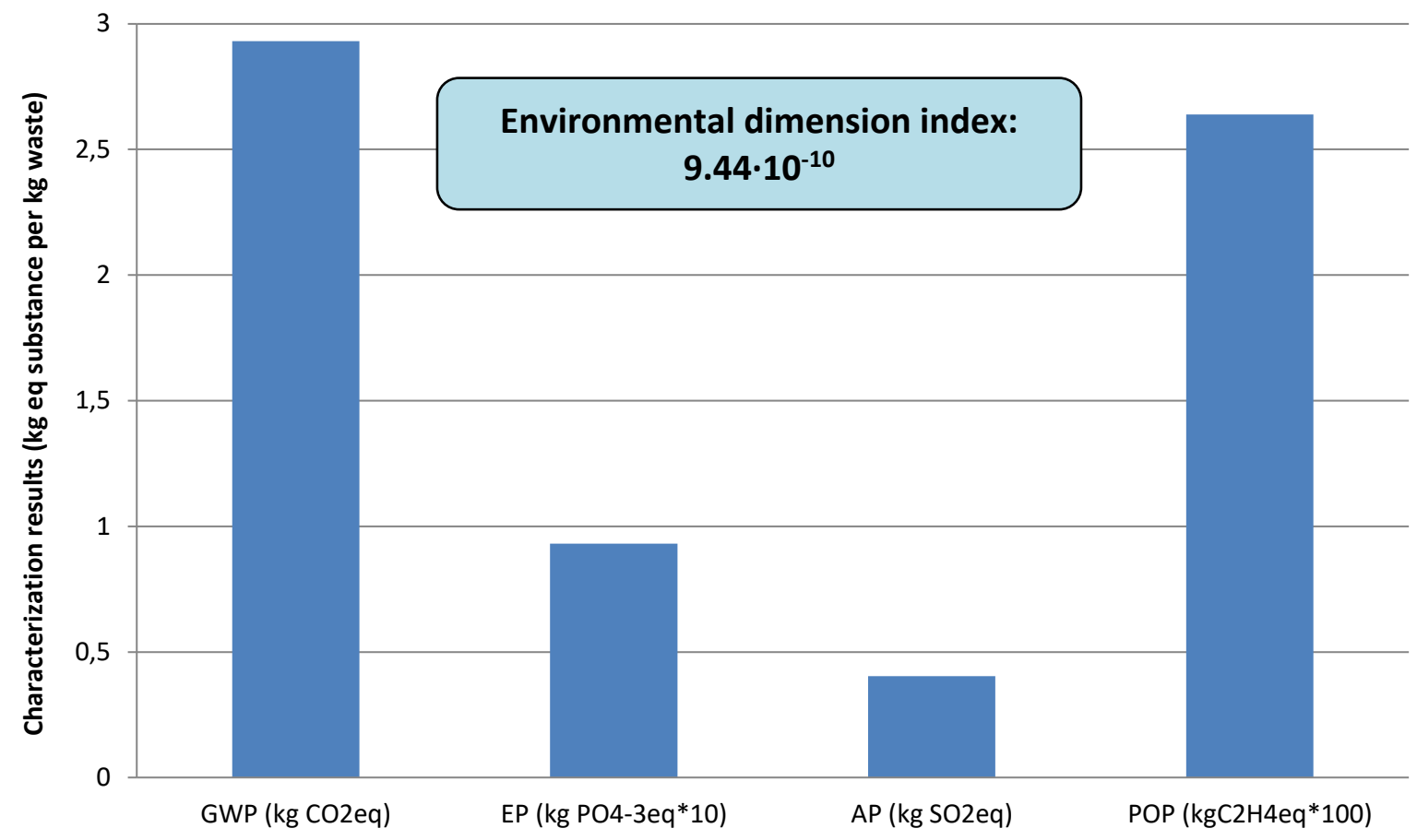

Figure 9. Environmental profile associated with the production of succinic acid from apple waste

Production of wasted chemicals ( $\sim 5 \%$ of total dose) is responsible for $13 \%$, $37 \%, 37 \%$ and $64 \%$ of total contributions to GWP, AP, EP and POP, respectively. Contributions from production of electricity demand in the distillation process are $84 \%$, $56 \%, 46 \%$ and $31 \%$ of total GWP, AP, PE and POP, respectively. Thus, further optimisation activities should be focused on both processes to reduce electricity demand and, to identify alternative chemicals with a better environmental background or to increase the recovery ratio in the distillation process. As difference to other valorisation strategies reported in the literature for alternative agri-food wastes where pretreatment stage considerably affects the environmental profiles due to the consideration of autohydrolysis (González-García et al., 2016, 2018; Gullón et al., 2018), in the succinic acid production system under study, it is not required a specific pretreatment process due to the characteristics of the raw material considered for valorisation (apple pomace) since it presents a huge amount of soluble sugars and a high susceptibility to the enzymatic hydrolysis.

Others methods for the purification of succinic acid have been suggested in the literature including electrodialysis, precipitation with ammonia or calcium hydroxide, 
pre-dispersed solvent extraction with colloidal liquid aphrons or ion exchange as alternative to the use of organic solvents (Kurzrock and Weuster-Botz, 2010). The analysis of their effect on the environmental profile derived from succinic acid production should be analysed to identify more attractive production routes from an environmental approach.

It is important to bear in mind that it has not been included in Figure 9 the environmental burdens linked to the production of the enzymes dose required in SS2. The rationale behind this decision is that enzymes production process (background process) has not been included in other studies available in the literature focused on butanedioic acid production (Moussa et al., 2016; Smidt et al., 2016). Thus, its consideration should complicate a direct comparison between environmental results. However and according to our results, the enzymes production process should be considered since it is a high-energy intensive process (Gilpin et al., 2017). Therefore, including the production of enzymes dose in the environmental profile, the environmental burdens should considerably be increased being 95 times higher in terms of GWP, 4 times higher in the remaining categories. Thus, special attention must be paid into the enzymes production process considered for analysis since it plays an environmental key role.

\subsection{Social sustainability of bioproducts}

One of the main challenges of this chapter is the assessment of social dimension of both bioproducts production chains considered for analysis. Since social dimension can be assessed considering different indicators or strategies, the profiles have been analysed taking into account the social indicators reported in Figure 3.

Firstly, social information must be gathered. Thus, specific questionnaires were designed and supplied to different related stakeholders (workers, consumers and general society). It is important to bear in mind that both scenarios proposed for analysed are carried out at pilot scale or simulated. Thus, stakeholders related with similar bioproducts manufacturing were interviewed. Information related with stakeholders is not reported in this chapter due to confidential issues.

\section{Aggregation and quantification of indicators}


The sub-categories selected for analysis are qualitative (i.e., Yes/No presentation) or semi-quantitative. Thus, the qualitative ones were converted into semiquantitative by means of a scoring strategy being the mark 1 allocated to the "No" answer and the mark 3 to the "Yes" answer. Regarding the semi-quantitative ones, the scores 1 (worse value)-2-3 (best value) were marked by the stakeholders according to their feelings and knowledge regarding the topic. According to it, it was possible to obtain a quantitative final score to each sub-category and indicator as well as to estimate the Social dimension index.

All the indicators were aggregated in order to come to one overall quantitative score for the impact on the social dimension. It is important to remark here that each pathway of social well-being considered (Safety, security and tranquillity, equality and autonomy) contributes equality (1/3) to the estimation of the final social score.

The aggregated score for each indicator $(I)$ was calculated as the arithmetical mean of the weighted value of involved sub-categories $(S c)$ taking into account the sample of stakeholders, the scores marked by each stakeholder and the number of subcategories per indicator (Equation 1 and Equation 2). Following, the social index $(S)$ is estimated considering the results obtained in each social pathway (Equation 3) by means of an arithmetical mean (Equation 4) and taking into account the number of indicators considered per pathway.

$$
\begin{array}{lr}
S c_{y}=\sum_{i=1}^{n} v_{i} \cdot \frac{1}{n} & \text { Equation 1 } \\
I_{z}=\sum_{y=1}^{j} S c_{y} \cdot \frac{1}{j} & \text { Equation 2 } \\
P_{x}=\sum_{z=1}^{t} I_{z} \cdot \frac{1}{t} & \text { Equation 3 } \\
S=\sum_{x=1}^{3} P_{x} \cdot \frac{1}{3} & \text { Equation 4 }
\end{array}
$$

where $v_{i}$ is the score marked by the stakeholder $i, S c_{y}$ is the average value of a subcategory $y, I_{z}$ is the average value of an indicator $z, P_{x}$ is the value corresponding to the social pathway $x, S$ is the Social dimension score, $n$ is the number of stakeholders that constitute the sample, $j$ is the number of sub-categories that constitute an indicator, $t$ is the number of indicators that constitute a social pathway and $x$ is the number of social pathways. 


\section{Social dimension results}

According to the questionnaires supplied by the consulted stakeholders, the results obtained per scenario under assessment taking into account social issues are displayed in Figure 10.

Social indicators such as Health and safety, Transparency, Fair salary and Contributions to economic development report higher scores for the prebiotics and antioxidant extracts production than for succinic acid production. On the contrary, the succinic acid production derives into a better profile in terms of Equal opportunities/discrimination and Benefits of bioproduct. The consideration of succinic acid of a "top chemical" could be associated with the social perception regarding this bioproduct since the other two are related with food and pharmaceutical uses. However, it must be highlighted that not so outstanding differences are identified in Public dedication to sustainability issues $(\sim 3 \%)$.

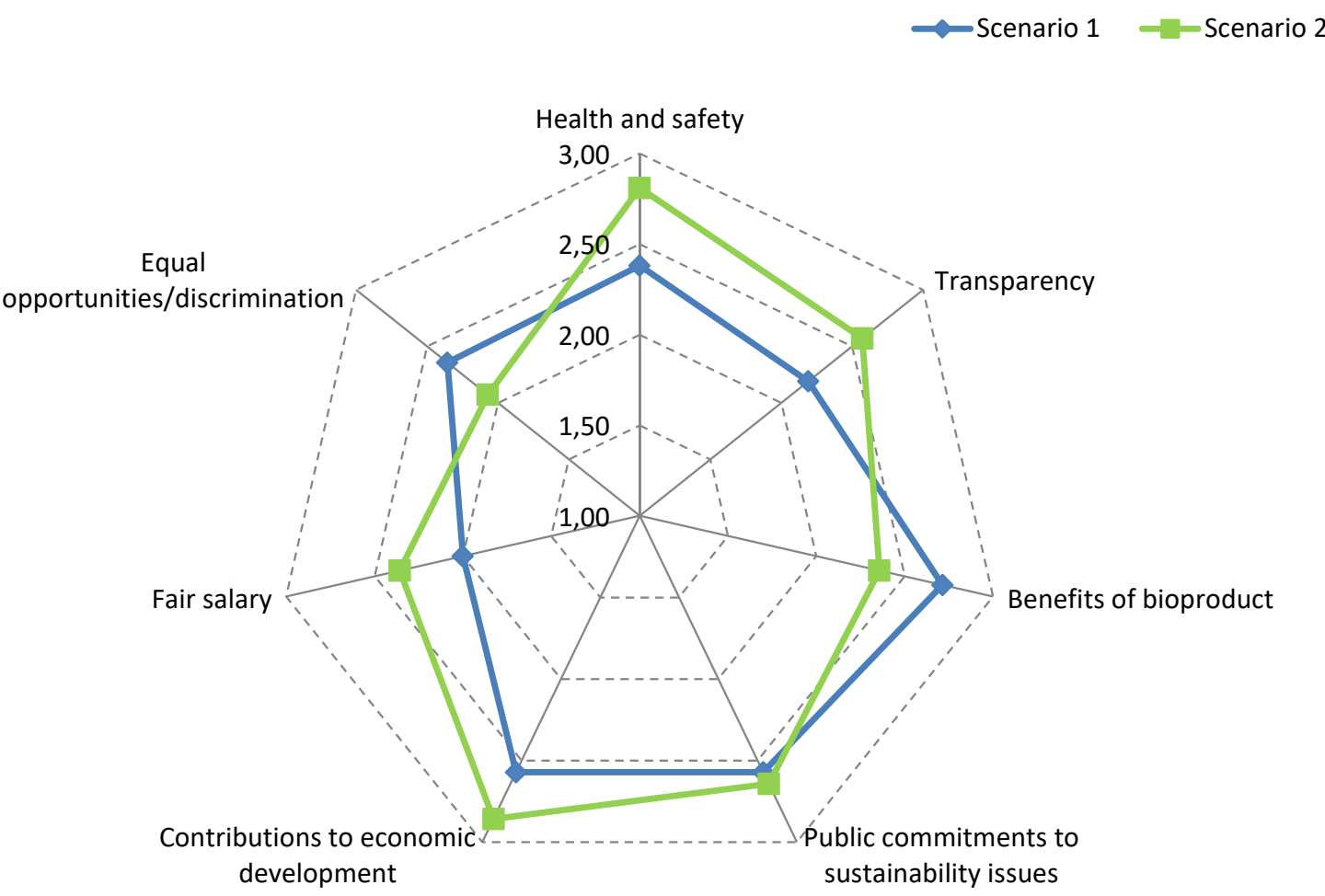

Figure 10. Social results per social indicators considered for analysis. Scenario 1 Succinic acid production; Scenario 2 - Oligosaccharides and antioxidants production

Regarding the social results per assessed stakeholder, Figure 11 displays the comparative scores and regardless the stakeholder, the production of oligosaccharides 
and antioxidant is better scored. The consideration of oligosaccharides as prebiotics and their nutraceutical and pharmaceutical properties are behind the results obtained from consumers and general society. Regarding the scores obtained from workers, they are very similar since there are not remarkable differences between manufacturing stakeholders consulted.

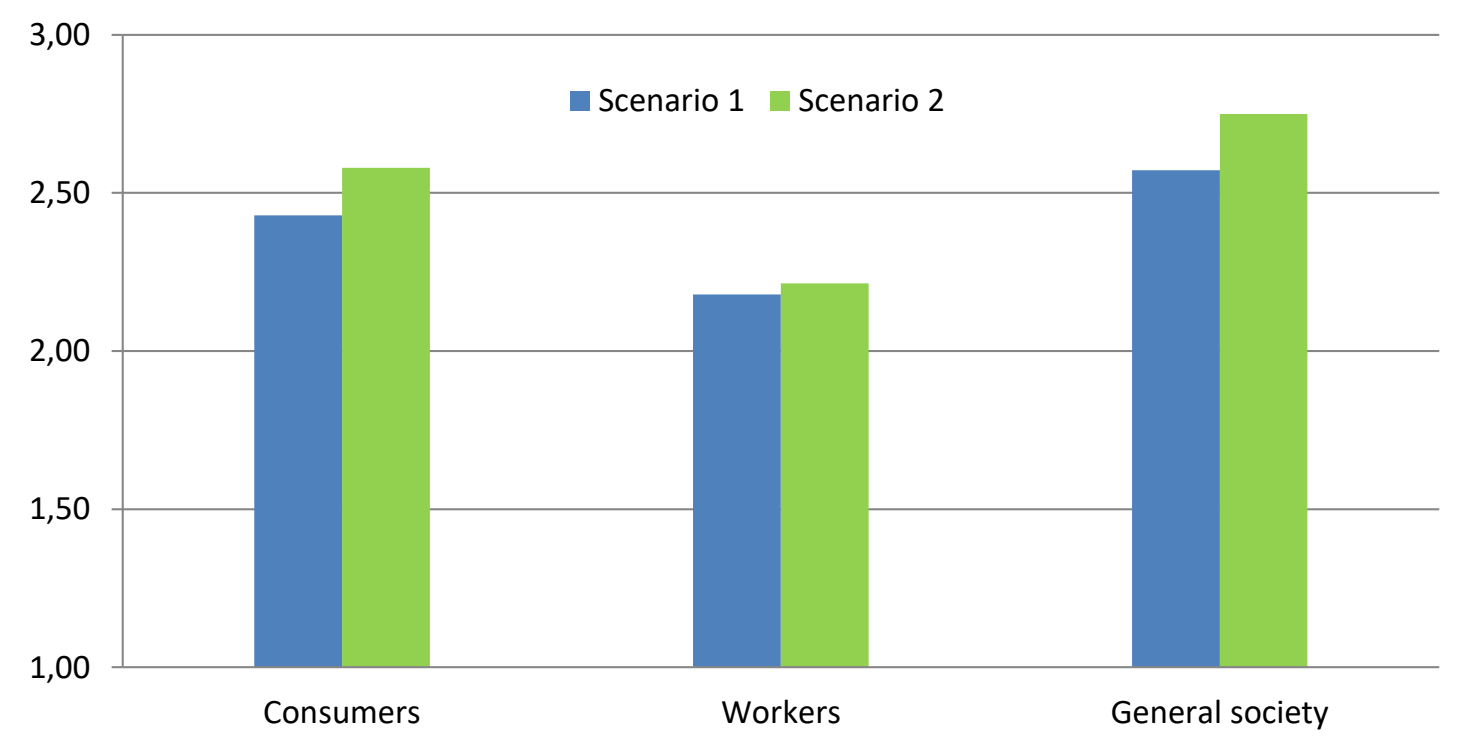

Figure 11. Comparative social scores per stakeholder

According to Figure 12, the production of oligosaccharides and antioxidant extract from agri-waste reports a better social perception (6\% higher) than the succinic acid based scenario. The rationale behind of these results could be linked to the characteristics of the bioproducts since prebiotics belongs to pharmaceutical and nutraceutical sectors and nowadays the society is considerably concerned by health and overall quality of life, demanding novel functional products with ability to prevent diseases and to maintain the human health. 


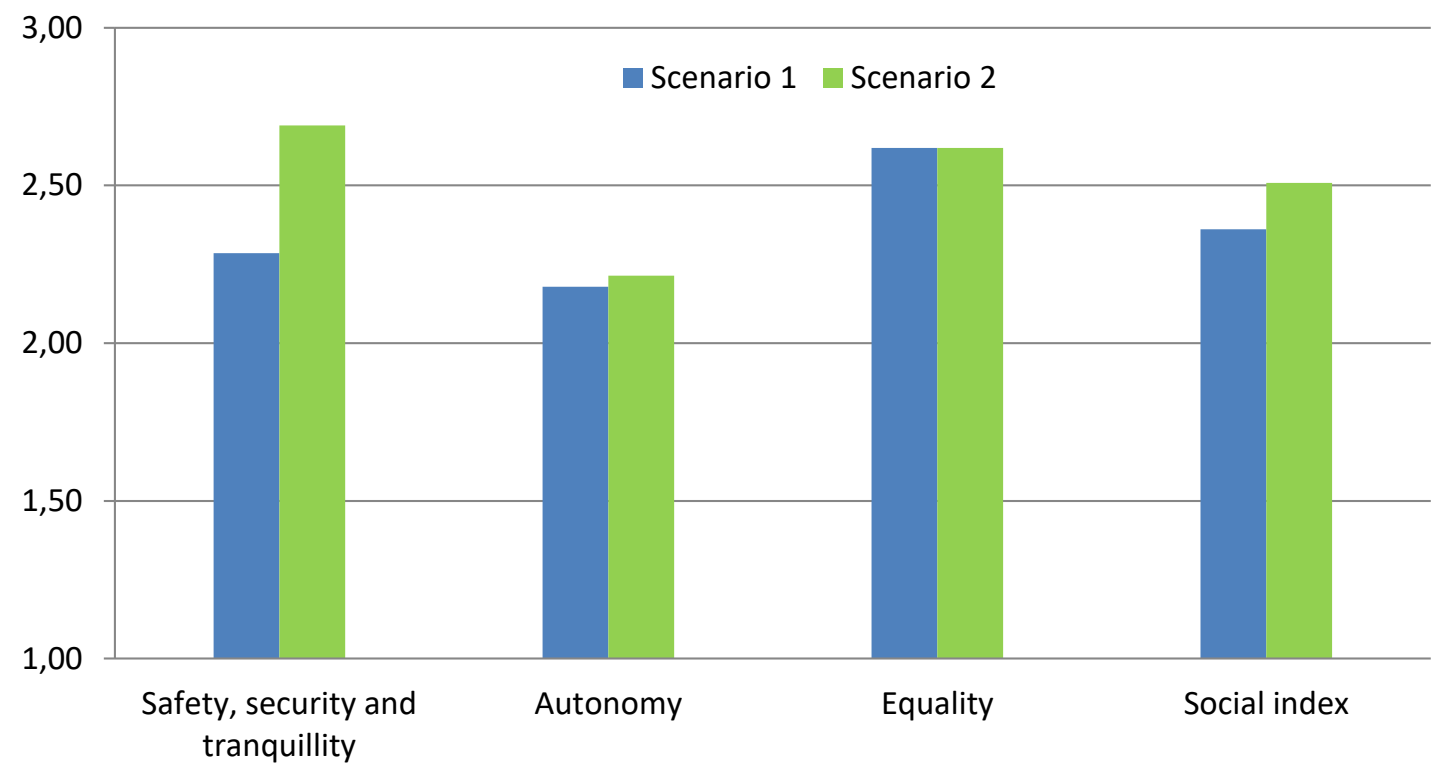

Figure 12. Social results per social pathways and global social index (S). Scenario 1 Succinic acid production; Scenario 2 - Oligosaccharides and antioxidants production

\section{Conclusions and future Outlook}

Nowadays special attention is being paid to bioproducts obtaining from agrifood residues not only due to their potential uses as alternative compounds to conventional fossil ones but also due to the valorisation of an organic waste from circular economy and biorefinery approaches.

Environmental benefits have been assessed in this chapter as well as in the literature. However, other issues need to be addressed to demonstrate their sustainability regardless conventional products. Therefore, it is imperative to have tools or methodologies for sustainability assessment taking into account social and economic pillars.

Thus, the environmental pillar has been complemented in this chapter with the social one to analyse two different biorefinery scenarios focused on the valorisation of different agri-food wastes i.e. vine shoots and apple pomace. In addition, a methodology to analyse the social dimension has been formulated considering multiple social subcategories related with social well-being.

Nevertheless and in order to obtain a final sustainability index, further research is required focused on the assessment of the economic pillar. 


\section{Acknowledgements}

This research has been financially supported by Xunta de Galicia (project ref. ED431F 2016/001), the Spanish Ministry of Economy and Competitiveness (CTQ2016-81848REDT) and the STAR-ProBio project funded by the European Union's Horizon 2020 Program (Grant agreement No. 727740). S.G-G., P.G. \& B.G. would like to express their gratitude to the Spanish Ministry of Economy and Competitiveness for financial support (Grant references RYC-2014-14984, IJCI-2015-25304 and IJCI-2015-25305, respectively). The authors S.G-G. \& B.G. belong to the Galician Competitive Research Group GRC 2013-032, programme co-funded by FEDER as well as to CRETUS (AGRUP2015/02).

\section{References}

Agócs, A., Nagy, V., Szabó, Z., Márk, L., Ohmacht, R., Deli, J. (2007). Comparative study on the carotenoid composition of the peel and the pulp of different citrus species. Innovative Food Science and Emerging Technologies, 8, 390-394.

Alañón, M. E., Alarcón, M., Marchante, L., Díaz-Maroto, M. C., Pérez-Coello, M. S. (2017). Extraction of natural flavorings with antioxidant capacity from cooperage byproducts by green extraction procedure with subcritical fluids. Industrial Crops \& Products, 103, 222-232.

Alkotaini, B., Koo, H., Kim, B. S. (2016). Production of polyhydroxyalkanoates by batch and fed-batch cultivations of Bacillus megaterium from acid-treated red algae. Korean Journal of Chemical Engineering, 33, 1669-1673.

Al-Salem, S. M., Evangelisti, S., Lettieri, P. (2014). Life cycle assessment of alternative technologies for municipal solid waste and plastic solid waste management in the Greater London area. Chemical Engineering Journal, 244, 391-402.

Alvarado-Morales, M., Gunnarsson, I. B., Fotidis, I. A., Vasilakou, E., Lyberatos, G., Angelidaki, I. (2015). Laminaria digitata as a potential carbon source for succinic acid and bioenergy production in a biorefinery perspective. Algal Research, 9, 126-132.

Aparicio, S., Alcalde, R. (2009). The green solvent ethyl lactate: an experimental and theoretical characterization. Green Chemistry, 11, 65-78. 
Ayala-Zavala, J. F., Vega-Vega, V., Rosas-Domínguez, C., Palafox-Carlos, H., Villa-Rodriguez, J. A., Wasim Siddiqui, Md., Dávila-Aviña, J. E., González-Aguilar, G. A. (2010). Agro-industrial potential of exotic fruit byproducts as a source of food additives. Food Research International, 44, 1866-1874.

Banerjee, J., Singh, R., Vijayaraghavan, R., MacFarlane, D., Patti, A. F., Arora, A. (2017). Bioactives from fruit processing wastes: Green approaches to valuable Chemicals. Food Chemistry, 225, 10-22.

Barba, F. J., Zhu, Z., Koubaa, M., Sant'Ana, A. S., Orlien. V. (2016). Green alternative methods for the extraction of antioxidant bioactive compounds from winery wastes and by-products: A review. Trends in Food Science and Technology, 49, 96-109.

Baysal, T., Ersus, S., Starmans, D. A. (2000). Supercritical $\left(\mathrm{CO}_{2}\right)$ extraction of $\beta$ carotene and lycopene from tomato paste waste. Journal of Agricultural and Food Chemistry, 48, 5507-5511.

Bechtold, I., Bretz, K., Kabasci, S., Kopitzky, R., Springer, A. (2008). Succinic acid: a newplatform chemical for biobased polymers from renewable resources. Chemical Engineering Technology, 31, 647-654.

Blaga, S. (2013). Corporate Social Responsibility from a Romanian perspective. Publisher: University Babes-Bolay Press, Cluj-Napoca, Romania. ISBN 978-973-595540-3.

Blok, K., Huijbregts, M., Patel, M.K., Hertwich, E., Hauschild, M., Sellke, P., Antunes, P., Hellweg, S., Mays, C., Ciroth, A., Harmelink, M.; Ramirez, C. A.; Gaasbeek, A.; Meijer, E. (2013). Utrecht University Repository (Book). Report prepared within the EC 7th Framework (Project $\left.n^{\circ}: 227078\right)$, Project title: Development and application of a standardized methodology for the PROspective SUstaInability assessment of Technologies.

Bond, A. J., Morrison-Saunders, A. (2011) Re-evaluating sustainability assessment: aligning the vision and the practice. Environmental Impact Assessment Review, 31, 1-7.

Bozell, J. J., Petersen, G. R. (2010). Technology development for the production of biobased products from biorefinery carbohydrates-the US Department of Energy's “Top10” revisited. Green Chemistry, 12, 539-554. 
Budzianowski, W. M., Postawa, K. (2016). Total Chain Integration of sustainable biorefinery systems. Applied Energy, 184, 1432-1446.

Cesário, M. T., da Fonseca M., Manuela, R., Marques, M. M., de Almeida, M., Catarina, M.D. (2018). Marine algal carbohydrates as carbon sources for the production of biochemicals and biomaterials. Biotechnology Advances, 36, 798-817.

Chun, Y., Yunxiao, L., Ashok, S., Seol, E., Park, S. (2014). Elucidation of Toxicity of Organic Acids Inhibiting Growth of Escherichia coli W. Biotechnology and Bioprocess Engineering, 19: 858-865.

Dávila, D., Gordobil, O., Labidi, J., Gullón, P. (2016). Assessment of suitability of vine shoots for hemicellulosic oligosaccharides production through aqueous processing. Bioresource Technology, 211, 636-644.

Deng, G. F., Shen, C., Xu, X. R., Kuang, R. D., Guo, Y. J., Zeng, L. S., Gao, L. L., Lin, X., Xie, J. F., Xia, E. Q., Li, S., Wu, S., Chen, F., Ling, W. H., Li, H. B. (2012). Potential of fruit wastes as natural resources of bioactive compounds. International Journal of Molecular Sciences, 13, 8308-8323.

Doka, G. (2007). Life cycle inventories of waste treatment services. Ecoinvent Report No 13 (Dübendorf, Switzerland).

dos Santos, T. C., Gomes, D. P. P., Bonomo, R. C. F., Franco, M. (2012). Optimisation of solid state fermentation of potato peel for the production of cellulolytic enzymes. Food Chemistry, 133, 1299-304.

Fava, F., Totaro, G., Diels, L., Reis, M., Duarte, J., Beserra Carioca, O., PoggiVaraldo, H. M., Ferreira, B. S. (2013). Biowaste biorefinery in Europe: opportunities and research \& development needs. New Biotechnology, 32, 100-108.

Fernández-Bolaños, J., Rodríguez, G., Gómez, E., Guillén, R., Jiménez, A., Heredia, A., Rodríguez, R. (2004). Total recovery of the waste of two-phase olive oil processing: isolation of added-value compounds. Journal of Agricultural and Food Chemistry, 52, 5849-55.

Fitzpatrick, S. W. (2006). The Biofine Technology: A "Bio-Refinery" Concept Based on Thermochemical Conversion of Cellulosic Biomass. ACS Symposium Series, 921, 271-287. 
Galanakis, C. M. (2012). Recovery of high added-value components from food wastes: Conventional, emerging technologies and Commercialized applications. Trends in Food Science \& Technology, 26, 68-87.

Gilani, B., Stuart, P. R. (2015). Life cycle assessment of an integrated forest biorefinery: hot water extraction process case study. Biofuels, Bioproducts and Biorefining, 9, 677-695.

Gilpin, G., Andrae, A. S. G. (2017). Comparative attributional life cycle assessment of European cellulase enzyme production for use in second-generation lignocellulosic bioethanol production. The International Journal of Life Cycle Assessment, 22, 10341053.

Goedkoop, M., Oele, M., Leijting, J., Ponsioen, T., Meijer, E. (2013). Introduction to LCA with SimaPro 8. PRé Consultants. The Netherlands.

Gómez, B., Gullón, B., Yañez, R., Parajó, J. C., Alonso, J. L. (2013). Pecticoligosacharides from lemon peel wastes: Production, purification and chemical characterization. Journal of Agricultural and Food Chemistry, 61, 10043-10053.

González-García, S., Gullón, B., Moreira, M. T. (2017). Environmental assessment of biorefinery processes for the valorization of lignocellulosic wastes into oligosaccharides. Journal of Cleaner Production, 172, 4066-4073.

González-García, S., Gullón, B., Rivas, S., Feijoo, G., Moreira, M. T. (2016). Environmental performance of biomass refining into high-added value compounds. Journal of Cleaner Production, 120, 170-180.

González-Paramás, A. M., Esteban-Ruano, S., Santos-Buelga, C., de PascualTeresa, S., Rivas-Gonzalo, J. C. (2004). Flavanol Content and Antioxidant Activity in Winery Byproducts. Journal of Agricultural and Food Chemistry, 52, 234-238.

Grajek, W., Olejnik, A., Sip, A. (2005). Probiotics: Prebiotics and antioxidants as functional foods. Acta Biochimica Polonica, 52, 665-671.

Griggs, D., Stafford-Smith, M., Gaffney, O., Rockström, J., Öhman, M. C., Shyamsundar, P., Steffen, W., Glaser, G., Kanie, N., Noble, I. (2013). Policy: sustainable development goals for people and planet. Nature, 495, 305-307.

Guinée, J. B., Gorrée, M., Heijungs, R., Huppes, G., Kleijn, R., de Koning, A., van Oers, L., Wegener, A., Suh, S., Udo de Haes, H. A. (2001). Life Cycle Assessment. An 
Operational Guide to the ISO Standards. Centre of Environmental Science, Leiden, The Netherlands.

Gullón, B., Eibes, G., Moreira, M. T., Dávila, I., Labidi, J., Gullón, P. (2017). Antioxidant and antimicrobial activities of extracts obtained from the refining of autohydrolysis liquors of vine shoots. Industrial Crops \& Products, 107, 105-113.

Gullón, B., Gullón, P., Sanz, Y., Alonso, J. L., Parajó, J. C. (2011). Prebiotic potential of a refined product containing pectic oligosaccharides. LWT - Food Science and Technology, 44, 1687-1696.

Gullón, B., Gullón, P., Tavaria, F., Pintado, M., Gomes, A. M., Alonso, J. L., Parajó, J. C. (2014). Structural features and assessment of prebiotic activity of refined arabinoxylooligosaccharides from wheat bran. Journal of Functional Foods, 6, 438-449.

Gullón, P., González-Muñoz, M. J., van Gool, M. P., Schols, H. A., Hirsch, J., Ebringerová, A., Parajó, J. C. (2010). Production, refining, structural characterization and fermentability of rice husk xylooligosaccharides. Journal of Agricultural and Food Chemistry, 58, 3632-3641.

Gullón, P., Gullón, B., Dávila, I., Labidi, J., Gonzalez-Garcia, S. (2018). Comparative environmental Life Cycle Assessment of integral revalorization of vine shoots from a biorefinery perspective. Science of the Total Environment, 624, 225-240.

Hollmann, J., Lindhauer, M. G. (2005). Pilot-scale isolation of glucuronoarabinoxylans from wheat bran. Carbohydrate Polymers, 59, 225-230.

Hwang, H. J., Kim, S. M., Chang, J. H., Lee, S. B. (2012). Lactic acid production from seaweed hydrolysate of Enteromorpha prolifera (Chlorophyta). Journal of Applied Phycology, 24, 935-940.

Ilmen, M., Koivuranta, K., Ruohonen, L., Suominen, P., Penttila, M. (2007). Efficient production of L-lactic acid from xylose by Pichia stipitis. Applied and Environmental Microbiology, 73, 117-123.

Iribarren, D., Martín-Gamboa, M., O’Mahony, T., Dufour, J. (2016). Screening of socio-economic indicators for sustainability assessment: a combined life cycle assessment and data envelopment analysis approach. The International Journal of Life Cycle Assessment, 21, 202-214. 
ISO 14044 (2006). Environmental Management e Life Cycle Assessment e Principles and Framework. International Organization for Standardization.

ISO 14045 (2012). Environmental management-eco-efficiency assessment of product systems-principles, requirements and guidelines. International Organization for Standardization, Geneva.

Jørgensen, A., Le Bocq, A., Nazarkina, L., Hauschild, M. (2008). Methodologies for Social Life Cycle Assessment. The International Journal of Life Cycle Assessment, $13,96-103$

Jung, K. A., Lim, S. R., Kim, Y., Park, J. M. (2013). Potentials of macroalgae as feedstocks for biorefinery. Bioresource Technology, 135, 182-190.

Kam, B. (2009). Carbohydrate-based food processing wastes as biomass for biorefining of biofuels and chemicals Chapter 20 in: Handbook of Waste Management and Co-Product Recovery in Food Processing. Volume 2. A volumen in Woodhead Publishing Series in Food Science, Technology and Nutrition, Pp. 479-514.

Kemppainen, K. (2015). Production of sugars, ethanol and tannin from spruce bark and recovered fibres. (Doctoral Thesis, Aalto University, Department of Biotechnology and Chemical Technology, Finland). ISBN 978-951-38-8215-0 (electronic). http://www.vtt.fi/inf/pdf/science/2015/S76.pdf

Kralisch, D., Ott, D., Gericke, D. (2014). Rules and benefits of Life Cycle Assessment ingreen chemical process and synthesis design: a tutorial review. Green Chemistry, 17, 123-145.

Kurzrock T., Weuster-Botz, D. (2010). Recovery of succinic acid from fermentation broth. Biotechnololgy Letters, 32, 331-339.

Lama-Muñoz, A., Romero-García, J. M., Cara, C., Moya, M., Castro, E. (2014). Low energy-demanding recovery of antioxidants and sugars from olive stones as preliminary steps in the biorefinery context. Industrial Crops and Products, 60, 30-38.

Lavelli, V., Torresanim M. C. (2011). Modelling the stability of lycopene-rich byproducts of tomatoprocessing. Food Chemistry, 125, 529-35.

Lenucci, M. S., Durante, M., Anna, M., Dalessandro, G., Piro, G. (2013). Possible use of the carbohydrates present in tomato pomace and in byproducts of the 
supercritical carbon dioxide lycopene extraction process as biomass for bioethanol production. Journal of Agricultural Food Chemistry, 61, 3683-3692.

Li, Q., Wang, D., Wu, Y., Li, W., Zhang, Y., Xing, J., Su, Z. (2010). One step recovery of succinic acid from fermentation broths by crystallization. Separation and Purification Technology, 72, 294-300.

Li, X., He, X., Lv, Y., He, Q. (2014). Extraction and functional properties of watersoluble dietary fiber from apple pomace. Journal of Food Process Engineering, 37, 293-298.

López-Garzón, C. S., van der Wielen, L. A. M., Straathof, A. J. J. (2014). Green upgrading of succinate using dimethyl carbonate for a better integration with fermentative production. Chemical Engineering Journal, 235, 52-60.

Lun, O. K., Wai, T. B., Ling, L. S. (2014). Pineapple cannery waste as a potential substrate for microbial biotranformation to produce vanillic acid and vanillin. International Food Research Journal, 21, 953-958.

Marín, F. R., Soler-Rivas, C., Benavente-García, O., Castillo, J., Pérez-Alvarez, J. A. (2007). By-products from different citrus processes as a source of customized functional fibres. Food Chemistry, 100, 736-741.

Marinho, G. S., Alvarado-Morales, M., Angelidaki, I. (2016). Valorization of macroalga Saccharina latissima as novel feedstock for fermentation-based succinic acid production in a biorefinery approach and economic aspects. Algal Research, 16, 102109.

Martínez, M., Gullón, B., Schols, H. A., Alonso, J. L., Parajó, J. C. (2009). Assessment of the production of oligomeric compounds from sugar beet pulp. Industrial and Engineering Chemistry Research, 48, 4681-4687.

Mazumdar, S., Lee, J., Oh, M. K. (2013). Microbial production of 2,3 butanediol from seaweed hydrolysate using metabolically engineered Escherichia coli. Bioresource Technology, 136, 329-336.

Mikami, K. (2013). Current advances in seaweed transformation. In: Baptista, G.R. (Ed.), An Integrated View of the Molecular Recognition and Toxinology - from Analytical Procedures to Biomedical Applications. InTech, pp. 324-347. 
Mohdaly, A. A., Sarhan, M. A., Smetanska, I., Mahmoud, A. (2010). Antioxidant properties of various solvent extracts of potato peel, sugar beet pulp and sesame cake. Journal of the Science of Food and Agriculture, 90, 218-226.

Monrad, J. K., Suárez, M., Motilva, M. J., King, J. W., Srinivas, K., Howarda, L. R. (2014). Extraction of anthocyanins and flavan-3-ols from red grape pomace continuously by coupling hot water extraction with a modified expeller. Food Research International, 65, 77-87.

Moreira, D., Gullón, B., Gullón, P., Gomes, A., Tavaria, F. (2016). Bioactive packaging using antioxidant extracts for the prevention of microbial food-spoilage. Food and Function, 7, 3273-3282.

Moussa, H. I., Elkamel, A., Young, S. B. (2016). Assessing energy performance of bio-based succinic acid production using LCA. Journal of Cleaner Production, 139, 761-769.

Müller-Maatsch, J., Bencivenni, M., Caligiani, A., Tedeschi, T., Bruggeman, G., Bosch, M., Petrusan, J., Van Droogenbroeck, B., Elst, K., Sforza, S. (2016). Pectin content and composition from different food waste streams. Food Chemistry, 201, 3745

Muranaka, Y., Suzuki, T., Sawanishi, H., Hasegawa, I., Mae, K. (2014). Effective Production of Levulinic Acid from Biomass through Pretreatment Using Phosphoric Acid, Hydrochloric Acid, or Ionic Liquid. Industrial and Engineering Chemistry Research, 53, 11611-11621.

Mushtaq, Q., Irfan, M., Tabssum, F., Qazi, J. I. (2017). Potato peels: a potential food waste for amylase production. Journal of Food Process Engineering, 40, 1251212520.

Muthaiyan, A., Hernandez-Hernandez, O., Moreno, F. J., Sanz, M. L., Ricke, S. C. (2012). Hydrolyzed caseinomacropeptide conjugated galactooligosaccharides support the growth and enhance the bile tolerance in lactobacillus strains. Journal of Agricultural and Food Chemistry, 60, 6839-6845.

Nadour, M., Michaud, P., Moulti-Mati, F., 2012. Antioxidant activities of polyphenols extracted from olive (Olea europaea) of chamlal variety. Applied Biochemistry and Biotechnology, 167, 1802-1810. 
Ndayishimiye, J., Chun, B. S. (2017). Optimization of carotenoids and antioxidant activity of oils obtained from a co-extraction of citrus (Yuzu ichandrin) by-products using supercritical carbon dioxide. Biomass and Bioenergy, 106, 1-7.

Neupane, B., Halog, A., Lilieholm, R. J. (2013). Environmental sustainability of wood-derived ethanol: a life cycle evaluation of resource intensity and emissions in Maine, USA. Journal of Cleaner Production, 44, 77-84.

Norris, C. B. (2014). Data for social LCA. The International Journal of Life Cycle Assessment, 19, 261-265.

Norris, C. B., Cavan, D. A., Norris, G. (2012). Identifying Social Impacts in Product Supply Chains: Overview and Application of the Social Hotspot Database. Sustainability, 4, 1946-1965

Orjuela, A., Orjuela, A., Lira, C.T., Miller, D.J. (2013). A novel process for recovery of fermentation-derived succinic acid: Process design and economic analysis, Bioresource Technology, 139, 235-241.

Padma, P. N., Anuradha, K., Nagaraju, B., Kumar, V. S., Reddy, G. (2012). Use of pectin rich fruit wastes for polygalacturonase production by Aspergillus awamori MTCC 9166 in solid state fermentation. Journal of Bioprocessing and Biotechniques 2, 2.

Panouillé, M., Ralet, M. C., Bonnin, E., Thibault, J. F. (2007). Recovery and reuse of trimmings and pulps from fruit and vegetable processing. In: Waldron KW, editor. Handbook of waste management and co-product recovery in food processing. Cambridge: Woodhead Publishing Limited, 417-47.

Pateraki, C., Patsalou, M., Vlysidis, A., Kopsahelis, N., Webb, C., Koutinas, A. A., Koutinas, M. (2016). Actinobacillus succinogenes: Advances on succinic acid production and prospects for development of integrated biorefineries. Biochemical Engineering Journal, 112 (2016) 285-303.

Pazmiño-Durán, E. A., Giusti M. M., Wrolstad, R. E., Glória, M. B. A. (2001). Anthocyanins from banana bracts (Musa X paradisiaca) as potential food colorants. Food Chemistry, 73, 327-332. 
Pinazo, J. M., Domine, M. E., Parvulescu, V., Petru, F. (2015). Sustainability metrics for succinic acid production: A comparison between biomass-based and petrochemical routes. Catalysis Today, 239, 17-24.

PRé Consultants (2017). SimaPro Database Manual-Methods library. The Netherlands.

Ramesh, T., Kalaiselvam, M., 2011. An experimental study on citric acid production by Aspergillus niger using Gelidiella Acerosa as a substrate. Indian Journal of Microbiology, 51, 289-293.

Ribeiro da Silva, L. M., Teixeira de Figueiredo, E. A., Silva Ricardo, N. M., Pinto Vieira, I. G., Wilane de Figueiredo, R., Brasil, I. M., Gomes, C. L. (2014). Quantification of bioactive compounds in pulps and by-products of tropical fruits from Brazil. Food Chemistry, 143, 398-404.

Ruiz, E., Gullón, B., Moura, P., Carvalheiro, F., Eibes, G., Cara, C., Castro, E. (2017). Bifidobacterial growth stimulation by oligosaccharides generated from olive tree pruning biomass. Carbohydrate Polymers, 169, 149-156.

Sabeena Farvin, K. H., Grejsen, H. D., Jacobsen, C. (2012). Potato peel extract as a natural antioxidant in chilled storage of minced horse mackerel (Trachurus trachurus): Effect on lipid and protein oxidation. Food Chemistry, 131, 843-851.

Sagar, N. A., Pareek, S., Sharma, S., Yahia, E. M., Lobo, M. G. (2017). Fruit and Vegetable Waste: Bioactive Compounds, Their Extraction, and Possible Utilization. Comprehensive Reviews in Food Science and Food Safety, 17, 512-531.

Sala, S., Anton, A., McLaren, S. J., Notarnicola, B., Saouter, E., Sonesson, U. (2017). In quest of reducing the environmental impacts of food production and consumption. Journal of Cleaner Production, 140, 387-398.

Sandhya, R., Kurup, G. (2013). Screening and isolation of pectinase from fruit and vegetable wastes and the use of orange waste as a substrate for pectinase production. International Research Journal of Biological Sciences, 2, 34-39.

Sauer, M., Porro, D., Mattanovich, D., Branduardi, P. (2008). Microbial production of organic acids: expanding the markets. Trends in Biotechnology, 26, 100-108.

Searcy, C. (2012). Corporate Sustainability Performance Measurement Systems: A Review and Research Agenda. Journal of Business Ethics, 107, 239-253. 
Seifi, M., Seifi, P., Hadizadeh, F., Mohajeri, S. A. (2013). Extraction of lycopene from tomato paste by ursodeoxycholic acid using the selective Inclusion complex method. Journal of Food Science, 78, 1680-1685.

Singh, A., Sabally, K., Kubow, S., Donnelly, D. J., Gariepy, Y., Orsat, V., Raghavan, G. S. V. (2011). Microwave-Assisted Extraction of Phenolic Antioxidants from Potato Peels. Molecules, 16, 2218-2232.

Smidt, M., den Hollander, J., Bosch, H., Xiang, Y., van der Graaf, M., Lambin, A., Duda. J.P. (2016). Life cycle assessment of biobased and fossil-based succinic acid, in: J. Dewulf, S. De Meester, R. Alvarenga (Eds.), Sustainability Assessment of Renewables-Based Products: Methods and Case Studies, 307-322

Spangenberg, J. H. (2004). Reconciling sustainability and growth: criteria, indicators, policies. Sustainable Development, 12, 74-86.

Teixeira, A., Baenas, N., Dominguez-Perles, R., Barros, A., Rosa, E., Moreno, D. A., Garcia-Viguera, C. (2014). Natural bioactive compounds from winery by-products as health promoters: a review. International Journal of Molecular Sciences, 15(9), 15638-15678.

UNEP-SETAC (2009). Guidelines for social life cycle assessment of products. In: Benoît Norris C and Mazijn B, (eds.). United Nations Environment Programme (UNEP), Paris (France). Available from: http://www.unep.org/publications/

United Nations. 2015. Time for global action for people and planet. Sustainable Development Knowledge Platform. United Nations Department of Economic and Social Affairs. 2015. Available from: https://sustainabledevelopment.un.org/post2015.

Van Maris, A. J., Konings, W. N., van Dijken, J. P., Pronk, J. T. (2004) Microbial export of lactic and 3-hydroxypropanoic acid: Implications for industrial fermentation processes. Metabolic Engineering, 6, 245-255.

Vilas-Boas, S. G., Esposito, E., Mendonca, M. M. (2002). Novel lignocellulolytic ability of Candida utilis during solid-substrate cultivation on apple pomace. World Journal of Microbiology and Biotechnology, 18, 541-545.

Wang, X., Chen, Q., Lü, X. (2014). Pectin extracted from apple pomace and citrus peel by subcritical water. Food Hydrocolloids, 38, 129-137. 
Weidema, B. P. (2006). The integration of economic and social aspects in life cycle assessment. International Journal of Life Cycle Assessment, 11, 89-96.

Wernet,G., Bauer, C., Steubing, B., Reinhard, J., Moreno-Ruiz, E., Weidema, B. (2016). The ecoinvent database version 3 (part I): overview and methodology. The International Journal of Life Cycle Assessment, 21, 1218-1230.

Werpy, T., Petersen, G. (2004). Top value added chemicals from biomass - Results of screening for potential candidates from sugars and synthesis gas, vol. I, U.S.Department of Energy, Oak Ridge, http://www.osti.gov/bridge.

Wiloso, E. I., Heijungs, R., Huppes, G. (2014). A novel life cycle impact assessment method on biomass residue harvesting reckoning with loss of biomass productivity. Journal of Cleaner Production, 81, 137-145.

Zhang, Q., Nurhayati, Cheng, C. L., Nagarajan, D., Chang, J. S., Hu, J., Lee, D.J. (2017). Carbon capture and utilization of fermentation $\mathrm{CO}_{2}$ : Integrated ethanol fermentation and succinic acid production as an efficient platform. Applied Energy, 206, 364-37.

Zheng, Z., Shetty, K. (2000). Enhancement of pea (Pisum sativum) seedling vigour and associated phenolic content by extracts of apple pomace fermented with Trichoderma spp. Process Biochemistry, 36, 79-84. 